ISSN: $1130-3743$

\title{
UNA PEDAGOGÍA DE LA PRESENCIA. CRÍTICA FILOSÓFICA DE LA IMPOSTURA PEDAGÓGICA
}

\author{
A Pedagogy of Presence. Philosophical Critique \\ of Pedagogical Impostering
}

Une pédagogie de la présence. Critique philosophique
de l'imposture pédagogique

Fernando BÁRCENA ORBE

Universidad Complutense de Madrid. Facultad de Educación. Departamento de Teoría e Historia de la Educación. C/ Rector Royo Villanova, s/n. 28040 Madrid. Correo-e: fernando@edu.ucm.es

Fecha de recepción: marzo de 2012

Fecha de aceptación definitiva: julio de 2012

Biblid [(1130-3743) 24, 2-2012, 25-57]

\section{RESUMEN}

El propósito de este artículo es articular una reflexión filosófica en torno a una pedagogía de la presencia. Estar presentes en lo que nos pasa en un escenario educativo, como maestros o aprendices, como profesores o alumnos, supone poner en juego la atención y producir nuestra propia visibilidad en lo que hacemos y en lo que pensamos. Frente a la dominante tradición en filosofía de la educación, que define esta actividad como una mera construcción racional de la realidad educativa, a la que somete a un examen racional a partir del establecimiento de una distancia crítica con su objeto de conocimiento, se sugiere aquí la recuperación de la antigua tradición filosófica que define el trabajo filosófico (sobre la educación) como una forma de vida o como un proceso de transformación del sujeto de la experiencia a partir del establecimiento de una distancia poética o apropiada con la realidad. La noción de "pedagogía de la presencia" pretende dar cuenta del establecimiento de 
dicha distancia, en la que el sujeto (que aprende) produce su propia presencia en la experiencia de su aprender. El artículo termina con un análisis crítico de la impostura pedagógica de cierto discurso pedagógico dominante en la actualidad, dentro del cual dicha presencia queda anulada.

Palabras clave: pedagogía de la presencia, filosofía de la educación, investigación educativa, impostura pedagógica, acontecimiento, aprender.

\section{SUMMARY}

The purpose of this paper is to articulate a philosophical reflection on a pedagogy of presence. To be present to what happens in an educational setting, as teachers or learners, as professors or students, or as researchers, is to bring into play our attention and produce our own visibility in what we do and what we think. Faced with a dominant tradition in philosophy of education, one which defines this activity as a mere rational construction of the educational reality in which rational testing establishes a critical distance between a subject and an object of knowledge, it is suggested here that an ancient philosophical tradition that defines the work of research, philosophical or not, as a way of life and as a process that transforms the subject of experience through the establishment of a poetic distance with reality, be recuperated. The notion of a "pedagogy of presence" is intended to account for the establishment of a proper distance in which the learning subject produces his or her own presence in their learning experience. The paper ends with a critical analysis of a certain pedagogical impostering, which annuls the presence referred to, common in the dominant educational discourse today.

Key words: pedagogy of presence, philosophy of education, educational research, pedagogical impostering, event, learning.

\section{SOMMAIRE}

Le but de cet article est l'articulation d'une réflexion philosophique autour d'une pédagogie de la présence. Être présent sur la scène éducative, en tant que maitres et disciples, enseignantes ou étudiants, ou chercheurs, suppose une mise en jeu de l'attention et une production de notre propre visibilité à ce que nous faisons et ce que nous pensons. Contre la tradition philosophique dominante dans la recherche pédagogique, qui définit cette activité comme une simple construction rationnelle de la réalité éducative, et qui la soumet à exploration après avoir établi une distance critique par rapport à son objet de connaissance, ce qui est ici suggéré est la récupération de l'ancienne tradition philosophique qui définit tout travail de recherche, philosophique ou non, comme manière de vivre ou comme processus de transformation du sujet de l'expérience par le biais de la création d'une distance poétique ou adéquate par rapport à la réalité. La notion de "pédagogie de la présence" prétend mise en place de la "bonne" distance, grâce à laquelle le sujet (qui apprend) produit sa propre présence dans l'expérience de son apprentissage. L'article aboutit à une 
analyse critique de l'imposture pédagogique du discours sur l'éducation actuellement dominant, dans lequel la présence est annulée.

Mots clés: pédagogie de la présence, philosophie de l'éducation, recherche éducative, imposture pédagogique, événement, apprendre.

Di tus cosas más personales, dilas, es lo único que importa, no te avergüences, las generales están en el periódico.

Elias Canetti

\section{INTRODUCCIÓN}

Un doble propósito anima este texto. Por una parte, se trata de articular una serie de reflexiones en torno a lo que aquí se denominará pedagogía de la presencia; y, por otra, elaborar una crítica filosófica al "saber pedagogista" que ha dado ya la entrada a una pedagogía posteducativa, a partir de lo que, siguiendo a Isabelle Stal (2008), denominaré la impostura pedagógica.

Voy a tratar de satisfacer ambos objetivos por dos vías. En primer lugar, contrastando dos tradiciones filosóficas rivales de la investigación educativa, con el fin de que el lector logre apreciar los matices diferenciadores entre una primera tradición -que se enfrenta al estudio de sus temas a partir de una distancia crítica con la realidad- y una segunda en la que la condición necesaria para la elaboración de un pensamiento educativo pasa por que el sujeto se haga presente en lo que piensa y en lo que hace, en la realidad que estudia ${ }^{1}$.

Si en la primera tradición lo examinado es la "realidad" a través de los poderes del pensamiento, en la segunda es la propia presencia en esa realidad, a través de lo que aquí se definirá como distancia poética, la condición necesaria para lograr sus propósitos. Lo real, aquí, no es meramente una cosa, sino un acontecimiento; no un problema, sino una cuestión abierta; no reclama tanto soluciones como respuestas a situaciones singulares; no es, en fin, representación sino un lugar de presencia. Lo real no queda reducido a lo que debería ser, sino que siempre es lo que, de hecho, ya es, el modo como se manifiesta (Larrosa, 2010, 109). Esta segunda tradición pone el acento, de una manera fundamental, en el "aprender" del sujeto de la experiencia, entendido como una especie de toma de conciencia o un caer en la cuenta.

1. Ambas tradiciones, en realidad, coinciden con lo que Foucault llamó el "momento cartesiano" y el "momento socrático" de la filosofía. Cfr. Foucault, 2002, 15-38. 
UNA PEDAGOGÍA DE LA PRESENCIA. CRÍTICA FILOSÓFICA DE LA IMPOSTURA PEDAGÓGICA

Quizá sorprenda la alusión a lo "poético" en esta segunda tradición. No se trata de invocar ningún esteticismo, ni procurar un embellecimiento del discurso filosófico en educación. En sus Observaciones, Wittgenstein decía, refiriéndose a su propia obra, que "creo haber resumido mi postura respecto a la filosofía al decir que la filosofía debería ser una obra poética" (Wittgenstein, 1989, 51). Para el filósofo austriaco, ética y estética son lo mismo, lo que, en el marco del Tractatus, significa que existe un vínculo o nexo entre la búsqueda de una justa visión del mundo (ejercitado en la contemplación) y las proposiciones que él mismo articula allí en forma literaria o aforística. El sentido (ético) que no se deja decir (lo indecible) en las proposiciones se muestra -encontrando su lugar apropiado-, bajo la forma estética, poética y literaria del aforismo (Gabriel, 2007, 139). De acuerdo con esto, para esta tradición -en la que lo ético y lo estético quedan articulados, hasta formar una composición existencial- el lenguaje (educativo) no sólo tiene la función de nombrar o designar sus objetos o realidades, o traducir los pensamientos (pedagógicos), sino que va en otra dirección: pues comprender el lenguaje, entender una frase o una formulación, está más cerca del acto de comprender, por así decir, "un tema musical". No habría, por tanto, como dice Hadot al referirse a la obra de Wittgenstein, tanto "el" lenguaje, sino "juegos del lenguaje", juegos que se sitúan "en la perspectiva de una determinada actividad, de una situación concreta o de una forma de vida" (Hadot, 2007, 19).

De acuerdo con Hans Ulrich Gumbrecht (2009), lo que es o está "presente", en su más simple acepción, es lo que "tenemos delante y podemos ver" (praeessere), esto es, lo que es tangible, corporalmente incluso. Producir (producere) la presencia es "llevar hacia delante", "empujar hacia delante", algo así como hacer nacer, llevar, crear, hacer aparecer algo: producir la presencia o tornar visible algo en el mundo. Pero la presencia no es una categoría únicamente referida al espacio, sino al tiempo. Existe la posibilidad de cierta "tangibilidad" en el orden temporal: podemos hacernos presentes en nuestro propio tiempo, en la generación de la que formamos parte y en la que estamos, inevitablemente, adscritos. Estar presente en algo es, dicho lo más sucintamente posible, prestar atención; estar atentos a lo que nos pasa (Stiegler, 2008; Stiegler, 2010).

La tentativa de recuperación (filosófica) de una cultura pedagógica de la presencia puede entenderse como un ejercicio de crítica de la metafísica occidental, entendida en su sentido más literal de la palabra: lo que está más allá de lo meramente físico. Este es el sentido de la metafísica que Gumbrecht apunta como primordial. En el campo de las humanidades, el impulso metafísico supone un gesto intelectual que trata siempre de ir más allá de lo que se considera como mera superficie física, como si lo que importase de verdad fuese el significado que siempre está del lado de lo profundo, de lo oculto o de cierta esencialidad. Con ese gesto, contribuimos a desmaterializar el mundo.

El enfoque de este texto es el específico de una filosofía de la educación. Como campo de estudio, la filosofía de la educación forma parte de las humanidades. Parte de la tesis de este texto es que si hay un rasgo que caracteriza la 
autocomprensión de las humanidades, como campo de saber, es la convicción, históricamente constatable, de que su tarea primordial, si no exclusiva, es atribuir significado a los fenómenos que analiza. Esta vocación comienza, probablemente, con la modernidad, al mismo tiempo que el cogito cartesiano se reproduce en diferentes dicotomías -espíritu/materia, mente/cuerpo, profundidad, superficie, significado/significante- en las cuales el primer polo del par es concebido como jerárquicamente superior al segundo. La consecuencia de este privilegio de la parte más espiritual (e inmaterial) de la dicotomía es una escisión categorial entre el ser y la apariencia, volviendo imposible la afirmación de que en la esfera de los asuntos humanos ser y aparecer coinciden; o dicho en los términos de Gumbrecht: una desmaterialización del mundo provocada por una radical separación entre el concepto y el acontecimiento, que es lo que excita y violenta siempre el pensamiento. Existe, pues, una "hipertrofia hermenéutica", un exceso de búsqueda de significación en el terreno de las humanidades -y un pensamiento filosófico de la educación no se escapa a sus efectos- que impediría una "cultura de la presencia" (Gumbrecht, 2010, 9). Lo que Gumbrecht propone pensar -y en este texto se asume como central para la pedagogía, su estudio, su investigación y enseñanza, y para el aprender- es lo más parecido a algo que George Steiner dijo en Presencias reales, cuando imaginaba una sociedad de encuentros primarios con la cultura y sus variadas producciones: "Un modo de educación, una definición de valores desprovista, en la mayor medida posible, de "metatextos". [...] Una ciudad para pintores, poetas, compositores, coreógrafos, no para críticos de arte, literatura, música o ballet, estén en la plaza pública o en la Academia" (Steiner, 1989, 19). En nuestro caso: una ciudad de aprendices capaces de estar atentos, de hacerse presentes tanto en su conocer como en su ignorancia.

Como se ha señalado que parte del propósito en este artículo es ofrecer una crítica del saberpedagogista a través de una crítica de la "impostura pedagógica", es conveniente ahora hacer algunas matizaciones iniciales sobre esta última noción.

Entre sus varias acepciones, una "impostura" es un "engaño con apariencia de verdad". Im-postura es, en un sentido primordial, un desorden -una ausencia correcta de posición o postura- con respecto a distintos elementos dentro del espacio. Referida la educación, una "im-postura" supone entonces un engaño que pretende hacer pasar por verdadero lo que no es, y que, en cuanto tal, desordena, descoloca o altera cierto ordenamiento natural de las cosas. En este sentido, una impostura es, también, una falacia, un razonamiento, sofístico, erróneo que pretende hacerse pasar por verdadero, siendo lo erróneo no tanto las conclusiones alcanzadas como el razonamiento mismo que se emplea. Querría aquí hablar, sin embargo, de estos engaños como algo que van más allá de una mera estructura lógica (falaz) de razonamiento. Engaños, pues, que, en su apariencia de afirmar ciertas verdades, imponen al discurso pedagógico una rigidez que altera cierta naturalidad del mismo.

En efecto, muchos de los discursos pedagógicos actualmente dominantes parecen asentados en una suerte de esencialismo según el cual lo que, por 
UNA PEDAGOGÍA DE LA PRESENCIA. CRÍTICA FILOSÓFICA DE LA IMPOSTURA PEDAGÓGICA

ejemplo, define la relación de aprendizaje entre maestro y discípulo, entre profesor y alumno, o entre el investigador y sus objetos de estudio es un saber pedagógico definido de acuerdo a categorías y condiciones que se determinan antes de la experiencia de la propia relación educativa. Contrariamente a esta posición, aquí se afirmará que es la experiencia de la relación pedagógica -el hacernos enteramente presentes en ella- lo que permite pensar el sujeto de la educación, y no a la inversa. Hablamos aquí de una "relación pedagógica" para referirnos no solamente a la que ocurre entre un profesor y un alumno, un maestro y un aprendiz, sino también a lo que pasa entre un estudioso de la educación (un investigador) y sus temas de estudio.

La crítica que aquí se pretende realizar de la impostura pedagógica le debe mucho a un efecto de "extrañamiento de la impotencia" (Agamben, 2011, 61) provocado por nuestras sociedades democráticas, bajo las condiciones de la llamada "Sociedad de aprendizaje". Aristóteles definió en el libro IX de la Metafísica la potencia (dýnamis) en estrecha relación con la "impotencia" (adynamía). Toda potencia es, al mismo tiempo, impotencia de lo mismo y respecto de lo mismo (de lo que es potencia) (Met., 1046a, 29-31). O lo que es igual: todo "poder hacer" es, siempre, un "poder de no hacer", de modo que lo que define la potencia humana es simultáneamente potencia de ser y de no ser, de hacer y de no hacer. Esto expone al hombre, por supuesto, al riesgo del error, pero a la vez le permite acumular y dominar libremente sus propias capacidades, y transformarlas en facultades (Agamben, 2011, 60). Pues bien, el poder democrático, que afecta de lleno a la llamada sociedad de aprendizaje, separa a los hombres, no sólo de lo que pueden hacer, sino de su poder de no hacer. Separado de su impotencia -es decir, "extrañándola" - y privado de la experiencia de lo que puede no hacer, el hombre, sorprendentemente, es menos libre y menos capaz de resistencia. Como dice Agamben: "El hombre de hoy se cree capaz de todo y repite su jovial "no hay problema" y su irresponsable "puede hacerse", precisamente cuando, por el contrario, debería darse cuenta de que está entregado de manera inaudita a fuerzas y procesos sobre los que ha perdido su control" (Agamben, 2010, 60). Es ciego frente a sus incapacidades. Según el principio, supuestamente democrático, de "flexibilidad" -que ha devenido en la cualidad privilegiada que el mercado exige de cada uno- el hombre puede ser una cosa y su contrario; cualquier cosa. De ahí que no deba extrañar la confusión de los oficios y de las vocaciones, de las identidades profesionales y de los roles sociales. Un ejemplo que nos es muy afín: en el ámbito universitario, de acuerdo con la última reforma de los planes de estudios, en virtud del mencionado principio de flexibilidad pedagógica, cualquier profesor ha de ser capaz de impartir cualquier tipo de asignatura porque la unidad de medida de su dedicación no es ya su potencia (lo que sabe y puede hacer) sino el famoso "crédito". O dicho de otro modo: no somos capaces de ejercer nuestra capacidad de no poder hacer, que es la otra cara de la potencia: nuestra im-potencia. 


\section{DOS TRADICIONES RIVALES DE LA INVESTIGACIÓN EDUCATIVA}

Poco a poco, y en los últimos años sobre todo, no me he venido sintiendo cómodo con expresiones como "investigación pedagógica". Y no es porque no crea que la educación sea un objeto digno de ser estudiado, pensado, leído o escrito, sino porque estas palabras que acabo de pronunciar (estudiar, pensar, leer, escribir) parece que se hayan vuelto impronunciables en determinados lenguajes pedagógicos, que piensan la investigación de sus temas como algo que ya no tiene que ver con la experiencia de un pensar que es el resultado, siempre, de aquello que violenta, fuerza o tensa el pensamiento: "La verdad nunca es el producto de una buena voluntad previa, sino el resultado de una violencia en el pensamiento" (Deleuze, 1996, 25). La verdad -también en la investigación educativa-depende de un encuentro casual, contingente, imprevisto, con algo que nos obliga a pensar y a buscar lo verdadero.

Es como si la investigación pedagógica hubiera desplazado su centro de interés, y con él transformado el lenguaje, hasta convertirlo en mero instrumento de comunicación: en vez de expresar pensamientos, tengo la impresión de que la investigación pedagógica habla solamente sobre determinadas experiencias, para ajustarlas a marcos de interpretación ya fijados de antemano, como pretendiendo demostrar posiciones ya de suyo inamovibles y seguras. Habla sobre experiencias, pero no a partir de ellas, es decir: no se habla ya ni se piensa, cuando se investiga, desde lo que las experiencias dan a pensar. Es como si el investigador en educación ya no se con-moviera, sino que simplemente argumentara, explicara, interpretara o demostrara aquello acerca de lo cual el investigador ya estaba previamente convencido. Es como si se partiera de una especie de "buena voluntad natural" en su búsqueda de la verdad, y a partir de ahí sólo bastase adoptar la decisión y el método capaz de vencer las influencias exteriores que desvían al pensamiento de su vocación inicial, haciendo que tome lo que es falso como verdadero. Se trataría, entonces, como sugiere Gilles Deleuze, de descubrir y organizar las ideas siguiendo un orden, que sería el propio del pensamiento. Un orden del pensamiento, o un pensamiento ordenado, un pensar que ordena porque sabe ya en qué consiste pensar si se procede con el método apropiado (Deleuze, 1996, 177).

Este argumento recuerda una entrada del libro Juan de Mairena, del poeta Antonio Machado. El maestro Mairena, dirigiéndose a sus alumnos en su clase de Retórica, les dice: "Para decir bien hay que pensar bien, y para pensar bien conviene elegir temas muy esenciales, que logren por sí mismos captar nuestra atención, estimular nuestros esfuerzos, conmovernos, apasionarnos, y hasta sorprendernos" (Machado, 2003, vol. 1, 123). Es como si el investigador en educación, o en humanidades, no estuviera, de verdad, disponible, porque da por sabido aquello acerca de lo cual piensa. En este caso, el investigador en educación necesita ir a su investigación bien pertrechado: de teorías, de paradigmas, de metodologías, de hipótesis. Es como si no fuera ya posible para el investigador pensar la educación exponiéndose a lo que hace mientras piensa y es pensado por ella. Como si todo lo 
que hay, en un mundo o en una realidad convertida en mero problema a resolver, no tuviera ya el empuje que nos fuerza a pensar. O como si la tarea fundamental del investigador -su búsqueda, su recherche- fuera solamente pensar lo que hay y no abrirse a lo que da a pensar. Aplicando estas reflexiones a un pensamiento filosófico de la educación, no estaría de más recordar aquí las siguientes palabras del filósofo barcelonés Miguel Morey: "Debemos desconfiar de cualquier caracterización de la filosofía que la vincule a la escritura sin tener en cuenta la lectura, o que la vincule a la lectura sin tener en cuenta la experiencia del pensamiento, o que la vincule con el pensamiento sin tener en cuenta la lectura y la escritura" (Morey, 2007, 278). Cambiemos la palabra "filosofía" por la de "investigación educativa", leamos de nuevo este fragmento y decidamos después si hay o no un fondo de verdad en lo que la cita anterior enuncia. El investigador del que aquí se habla es, hoy, una rara avis, una especie bastante extraña: no es el "hombre de buena conciencia" -aquel para el que la realidad es un problema que siempre tiene solución-, sino una "especie que se lamenta", un melancólico a la búsqueda de la verdad a través de los signos que le fuerzan a pensar y le conmueven.

El sociólogo e historiador de las ideas alemán Wolf Lepenies dice, a propósito de esta figura del melancólico, que se trata de un intelectual que se queja del mundo" (Lepenies, 2008, 27), alguien cuya tarea fundamental es pensar, y alguien que, para superar ese estado de lamento, con frecuencia da lugar a un pensamiento utópico que pretende crear un mundo y un estado de cosas mejor; una utopía cuya función, paradójicamente, es ahuyentar la melancolía de la que nace la utopía misma. De este modo, la prohibición que pesa sobre la melancolía en todas las utopías literarias se transforma, rápidamente, en la obligación de ser feliz, en una "organización del optimismo". Pues bien, la investigación científica, que encarna la figura del científico, se trate de una investigación pedagógica o de otra clase, describe la actividad intelectual como algo situado más allá de la melancolía y más acá de la utopía. El científico no se desespera del mundo -como le ocurre al melancólico-, sino que se esfuerza por explicarlo; y no piensa en utopías, sino que formula pronósticos. Su "política del espíritu" no se caracteriza ni por la desesperación ni por la esperanza, sino por su "buena conciencia". Cree que todo puede ser dicho y que todo puede ser explicado. Y en ese "todo" no deja espacio alguno para lo que puede ser descubierto, para lo que puede ser experimentado.

Uno no puede evitar hablar o pensar desde algún lugar. Siempre se habla, se piensa, y por tanto se investiga o se busca, desde un espacio y desde un tiempo. En el caso del autor de este texto, desde un lenguaje de filosofía de la educación. Así que mucho de lo que diré a continuación tiene que ver con una especie de aproximación más o menos filosófica de la investigación educativa. La filosofía de la educación es una especie de Bildungsroman y quizá por ello las preguntas del tipo “Qué es la filosofía de la educación?" revisten una dimensión ontológica que no se ajusta a la experiencia, específica de ella, del devenir. El asunto no mejoraría añadiendo a esta pregunta el interrogante hermenéutico: ¿qué significa?, que la vincularía a una cuestión de mera producción de interpretaciones. Si la primera 
pregunta está presidida por una invocación esencialista, la segunda conecta esta disciplina a la pretensión universalista de la interpretación, que busca la producción de significados. Lo que se gana en "significado" se pierde en "sentido", y acaba por olvidarse una relación con el mundo fundada en la producción de la presencia (Bárcena, 2011).

Deseo plantear la pregunta por la filosofía de la educación como algo que tiene que ver, no ya con la esencia o con la significación, sino con la relación entre experiencia y sentido. Y esta relación supone un interrogante poético (ni ontológico ni hermenéutico): ¿Cómo me hago presente en lo que hago y en lo que pienso? El propósito de un filosofar educativo no sería ya la pretensión de cambiar lo que hay, sino aprender a mirar lo que ya vemos, pero no nos damos cuenta: prestar atención a lo que hay haciéndonos presentes en la realidad. Esta suposición quizá requiere un estilo de escritura que toma el acontecimiento no como un caso más, sino como un pliegue de lo real, una ocasión única para pensar singularmente aquello que en el terreno de lo dado se escapa a los marcos de explicación establecidos.

En educación, como en otros campos, existen diversas tradiciones de investigación. Empleo esta palabra -tradición- en un sentido muy específico, parecido al siguiente:

Una tradición es un modelo de interpretaciones y juicios que una comunidad ha elaborado a través del tiempo. Es una dimensión inherente a toda acción humana. Nunca se puede abandonar del todo la tradición, aunque sí se puede criticar una tradición desde el punto de vista de otra. Tradición no se opone a razón. A menudo es un debate continuo y razonado sobre el bien de la comunidad o institución cuya identidad define (Bellah, 1989, 396).

Ser partícipe de una tradición de estudio, investigación y práctica es practicar una conversación bumana en la que distintas voces dialogan entre sí. Practicar esa conversación es discutir los principios y reglas que fundan la práctica que realizamos, es reinterpretarlos de continuo y a menudo tener que ponerlos en cuestión. Lo que se discute, y aquello acerca de lo cual se conversa, es la práctica misma, que es un lugar intermedio entre el individuo y la institución dentro de la cual se realiza la actividad. Y como ninguna práctica se realiza al margen de la vida social y política, los miembros de una tradición de estudio, investigación y práctica están sometidos a un buen número de presiones sociales, por lo que una tradición viva se somete a una modificación y unos ajustes relativamente constantes (Cua, 1998, 243-245).

Es importante ofrecer ahora una visión panorámica muy resumida de dos tradiciones filosóficas rivales en la investigación educativa. En la tradición dominante no es el sujeto, erigido como sujeto del conocimiento, quien se examina, sino su objeto, cierta parcela de la realidad educativa la que es sometida a examen, análisis o escrutinio. La realidad (educativa), tomada como mero objeto de conocimiento, es el referente principal. Lo que aquí se entiende por realidad no es sino un problema, una representación, algo que reclama cierta solución, pero no presencia. Y todo esto ocurre como si lo que de verdad interesase es garantizar que ese examen de la realidad se hiciese técnica y metodológicamente del modo más apropiado, es 
UNA PEDAGOGÍA DE LA PRESENCIA. CRÍTICA FILOSÓFICA DE LA IMPOSTURA PEDAGÓGICA

decir, eficazmente, anticipando los resultados. En esta tradición, el conocimiento (de la educación) es un mero momento epistemológico: todo pasa por el "conocer", pero no por el "experimentar" (Foucault, 2002). En educación, conocer es un momento de la acción, de la intervención, de la participación, de la innovación, de la transformación de la realidad. Se dice: no se accede al conocimiento de algo, o no se produce conocimiento, más que desde la acción, en el actuar, y nunca desde la condición del espectador (Rancière, 2008; Mondzain, 2007).

La acción se opone, como la participación, a la pasividad, que se asimila al espectador. El espectador es quien no actúa y quien no conoce. Por tanto: ser espectador es un mal. Se ha expropiado del espectador, y en su pasividad, la posibilidad de aportar algo a la búsqueda en que toda investigación debería consistir. Como si no bastase eso que Arendt decía en La condición humana: pensar en lo que hacemos (Arendt, 1993). Pensar en lo que hacemos es pararse a pensar en eso que hacemos, en eso que estamos; es caer en la cuenta, prestar atención (atender, quedarse quietos, demorarse en la acción o demorar el impulso del actuar). Mirar. Quedarse mirando (North, 2012; Puelles Romero, 2011).

Según la segunda tradición, marginal con respecto a la anterior, cuyas raíces se encuentran en el estilo de la antigua filosofía como forma de vida ${ }^{2}$, la experiencia de la educación, y la de su investigación como búsqueda, pasa por restablecer cierta condición del investigador como espectador: por esa atenta pasividad que consiste en estar a la espera, atento, y mirando. El espectador se hace presente en lo que pasa y en lo que le pasa. A pesar de todo lo que se diga en torno a la importancia del concepto de acción en educación y en la investigación pedagógica, es cierto que uno puede ser de lo más activo en un aula o en una investigación, activo técnica y metodológicamente, y sin embargo no saber habitar, o no haber habitado en absoluto, ninguno de esos espacios.

En su versión dominante, la investigación educativa queda encerrada en ese momento epistemológico, que es un momento parcialmente cartesiano -ideas claras y distintas-, un momento que ha desmaterializado el mundo. Por el contrario, la idea de la presencia -la presencia de un espectador atento en la realidad acerca de la cual busca pensar, para pensar de otro modo- rematerializa el mundo: lo habita. Algunos ejemplos pueden aclarar de qué se trata en esta tradición dominante de la investigación educativa (Masschelein, 2009; Martín y Barrientos, 2009).

En un número relativamente reciente del Journal of Philosophy of Education, dedicado al tema "Lo que los filósofos de la educación hacen (o deberían hacer)" (Ruitenberg, 2009), podemos leer que la filosofía de la educación es una "disciplina académica especializada en el análisis y la comprensión de amplios procesos de construcción de teorías y el examen de sus premisas de base, con el fin de examinar y revelar los valores que inciden a las prácticas humanas académicas" (Holma,

2. Sobre esta tradición, véanse: HADOT, 2000, 2004, 2006, 2009; NussBaum, 2003; NeHAMAS, 2005. 
2009, 325). Asimismo, se señala que su tema son «las cuestiones éticas y filosóficas perennes sobre la responsabilidad, así como problemas epistemológicos sobre el conocimiento y su justificación" (Holma, 2009, 325). En otro momento, se dice: "Es una tarea central de la filosofía de la educación examinar los marcos conceptuales que los académicos y los prácticos emplean para interpretar la experiencia, expresar sus propósitos, enmarcar problemas y conducir sus investigaciones" (Vokey, 2009, 339).

Según estas citas, argumentar, evaluar, explorar, contrastar teorias son actividades centrales del trabajo intelectual en esta visión dominante de la filosofía de la educación, entendida como una especie de meta-reflexión que contempla a la investigación educativa y a su práctica como un objeto de conocimiento. Esta tradición es heredera de una de las historias del pensamiento más consolidadas, que presenta a Descartes como el inicio de la modernidad. Es el momento en el que alguien se distancia de la realidad y se siente autorizado para mirarla desde sí. La imagen ideal del científico que observa tras un microscopio es la que mejor refleja el legado que vino al mundo de la mano de Descartes: poner un trozo de realidad bajo la lente y observarla como si fuera por primera vez, ajenos a toda clase de ídolos y prejuicios, anotando de un modo objetivo lo que vemos para sacar las conclusiones pertinentes después. Se trata, también, de una visión de la filosofía de la educación insertada en la tradición establecida por Kant, una tradición focalizada en las condiciones internas y las condiciones externas de validación de la producción del conocimiento. De este proceso de distanciamiento de la realidad, de tomar perspectiva y decir desde sí de modo independiente, objetivo y claro se pueden señalar muchas cosas, aunque tal vez la más destacable sea la siguiente: que es la Razón del hombre la que puede y debe alcanzar toda la realidad en la que el hombre se mueve.

De acuerdo con esta tradición, el trabajo filosófico se concibe (también en filosofía de la educación) como algo relacionado con el juicio, clasificación, categorización, justificación, selección, clarificación de conceptos, interpretación, explicación y, en este sentido, es "crítica" del mismo modo que está orientada a pretensiones de validez, tanto ético-normativas como epistemológicas. Es el investigador, o el pensador, entendido como un sujeto del conocimiento, quien sitúa a la realidad (la investigación educativa, la práctica educativa, las políticas educativas, etc.) bajo el examen de su propio pensamiento (teoría, conceptos, conocimiento); o dicho de otro modo: es la realidad, situada frente al sujeto que la piensa, la que es sometida a examen. El sujeto del conocimiento debe mantenerse lo más alejado posible de ella para observarla con objetividad. No hacerse "personalmente" presente en ella es la condición de posibilidad para acceder a la verdad de la realidad.

Tenemos, entonces, dos versiones de investigación educativa. Una, en la que el investigador se distancia de la realidad crítica y epistemológicamente para, desde esa distancia, someterla a examen. Esta tradición de investigación es un acceso a la realidad y a la verdad que se basa en el conocimiento, y se dirige al conocimiento. El carácter pedagógico de la investigación viene determinado por aspectos 
UNA PEDAGOGÍA DE LA PRESENCIA. CRÍTICA FILOSÓFICA DE LA IMPOSTURA PEDAGÓGICA

cognitivos; y otra, en la que el sujeto de la experiencia, haciéndose presente en la realidad, establece una distancia poética para someterse a examen a sí mismo. Esta tradición de investigación es un acceso a la realidad y a la verdad que pasa por estar parados, a la expectativa, algo que supone un estar atentos, algo que implica un darse cuenta, en lo real, de lo que nos pasa cuando algo nos acontece. El carácter pedagógico de la investigación no se limita a sus aspectos cognitivos - porque pensar es más que un proceso de cognición-, sino que incorpora elementos del arte y de la literatura (está existencial y estéticamente orientada); en definitiva, hace uso de todo aquello que hace que la realidad se con-mueva, todo lo que hace que se amplíe la densidad de lo real, todo lo que hace que lo real produzca resonancia en nosotros.

Esta tradición tiene un punto de partida doble desde el punto de vista de una filosofía de la educación: a) el contraste entre tradiciones de investigación y práctica; y b) la atención al presente.

1. Por una parte, creo que el proceso de convertirse en filósofo de la educación no consiste en un simple aprendizaje o dominio de una serie de destrezas técnicas, ni en adherirse a un determinado paradigma establecido o adaptarse a un conjunto de reglas metodológicas, sino en aprender a confrontar una tradición histórica de investigación y práctica educativas participando en sus debates y en sus diálogos. Estos diálogos conforman una gran conversación histórica en la que tan importante es aprender a conversar con nuestros contemporáneos como con nuestros predecesores. Es una conversación con los textos de esa tradición, y en este sentido consiste también en un aprendizaje de nuevos modos de leer y de pensar.

2. Por otro lado, interesa también insistir en cierta disposición, que llamaré atención al presente. Michel Foucault decía que aspiraba a ser un "diagnosticador del presente", y un diagnóstico es, como se sabe, la acción de reconocer una enfermedad a partir de sus síntomas. Podría decirse que esta disposición no es más que una actitud intelectual que busca prestar atención al presente, o como el propio Foucault decía en Las palabras y las cosas, "a nuestro suelo silencioso e ingenuamente inmóvil [...] sus rupturas, su inestabilidad, sus fallas" (Foucault, 1996, 14). En este sentido, la cuestión filosófica es la cuestión del presente, de ese presente que somos nosotros mismos. Y nada más lógico, entonces, que colocar en el centro de su tarea, más que lo intemporal, lo singular, o dicho en otros términos, la finitud. Aquí el acontecimiento y la experiencia son categorías claves para pensar la tarea de la filosofía de la educación; pues una experiencia es precisamente aquello que nos transforma, que nos impide ser siempre los mismos. Esta filosofía (de la educación) volcada a la atención al presente hace de ella una trabajo del pensamiento sobre sí mismo. Un trabajo que no busca tanto legitimar lo que ya sabemos sino a un pensar de otro modo. Es aquí donde este saber nos transforma, ayudándonos a devenir otros. Puede decirse, entonces, que la filosofía es una disciplina para la cual toda materia "extranjera" es apropiada y para la que cualquier materia propia debe ser asimismo extranjera. En este sentido, 
la tarea de una investigación filosófica de la educación no sería tanto descubrir nuevas verdades que estuvieran inscritas en el cielo eterno de las ideas, sino en aprender a mirar, o tornar visible, lo que de hecho tenemos delante pero cuya densidad e importancia no percibimos. Es algo así como hacer aparecer lo que está cerca, lo que es inmediato, lo que está tan íntimamente ligado a nosotros que, por esa misma razón, no percibimos. La antigua palabra poiêsis es lo que significó originalmente: hacer pasar algo del no ser al ser; hacer aparecer algo, llevar algo a la máxima presencia de sí.

Así pues, siempre que investigamos y pensamos en o sobre la educación, queremos saber algo sobre ella y sobre lo que aporta a la construcción de un discurso pedagógico. En educación, lo que se puede poner en práctica, dentro de un curso de acción, también se puede transformar en palabras, elaborar conceptos y discutirse inteligentemente. En la medida en que todo ello se haga con cierto rigor, seriedad y profundidad, esta discusión incluirá tanto descripciones generales de lo que se hace como recomendaciones acerca de lo que se puede o no se puede hacer en distintas situaciones más específicas. De este modo, el discurso pedagógico estará formado por teorías, o teorizaciones, educativas expresadas de forma más o menos formal. La investigación en filosofía de la educación se ocupa de todo ello, examinando el aparato conceptual que teóricos y practicantes de la educación adoptan cuando la piensan o cuando la hacen. Este examen implica la capacidad para hacerse preguntas, para realizar problematizaciones, y ejercer la crítica como una actitud ética que mira o atiende a la realidad, al presente (Moore, 1974 y Moore, 1982). Se trata de querer saber, no para confirmar lo que ya sabemos, sino para pensar de otro modo. Ahora bien, para querer saber hay que tomar posición, y este gesto no es sencillo. Para saber hay que saber lo que se quiere y al mismo tiempo hay que saber dónde se sitúa nuestro no saber. Ni en el demasiado-cerca ni en el demasiado-lejos vemos ni sabemos nada. Como dice el filósofo Georges Didi-Huberman: "Para saber hay que tomar posición, lo cual supone moverse y asumir constantemente la responsabilidad de tal movimiento. Ese movimiento es acercamiento tanto como separación: acercamiento con reserva, separación con deseo. Supone un contacto" (Didi-Huberman, 2008, 12). Hay, pues, que tomar posición, acertar con la distancia justa. La distancia que propongo con la realidad es una distancia poética.

Del mismo modo que en el campo de la literatura, por ejemplo, autores como Milan Kundera o Paul Auster han demostrado que es posible contar historias cotidianas formadas de puras "insignificancias", "casualidades" y "efectos imprevistos" sin caer en una especie de vulgaridad ausente de una idea narrativa directriz, así también en el terreno de la filosofía, y en el de una filosofía de la educación, podría demostrarse que es posible promover ideas, no desde una razón abstracta desvinculada del terreno pasional de la vida, sino desde experiencias concretas que reflejan los cambios culturales en los que nos hallamos inmersos, sin incurrir por ello en la lúdica banalidad atribuida al ingenio postmoderno más reciente, o en otras modalidades discursivas que se limitan a decir que lo que hay es lo que hay. Si 
UNA PEDAGOGÍA DE LA PRESENCIA. CRÍTICA FILOSÓFICA DE LA IMPOSTURA PEDAGÓGICA

esto es posible, entonces el punto de partida de este filosofar sería una afirmación de la pluralidad humana de las interpretaciones. Esta afirmación de la pluralidad interpretativa reclama un estilo de filosofía -de pensamiento y de escritura-- acorde con sus propósitos, uno que no toma el acontecimiento como un caso más, sino como un desvío, una "línea de fuga" y una oportunidad para pensar con mayor radicalidad aquello que en el terreno de lo dado escapa al orden del discurso y a marcos de explicación supuestamente fijos y firmes.

Ese estilo es el del ensayo, y la vocación ensayística del discurso filosófico -recordemos tanto a Montaigne como a Shopenhauer o a Nietzsche, por ejemplono nace de una debilidad resignada o desconsolada, sino de un empeño -ciertamente humilde pero al mismo tiempo confiado, sin ser ingenuo- por habilitar un espacio intermedio, reflexivo, limítrofe entre la finitud de la condición humana y su interminable ansia de saber (Adorno, 2003; Obaldia, 1995). El ensayo, así, más que pretender negarla, se erige en la forma expresiva que busca hacer justicia a la complejidad de lo real, se empeña en articular especulación y experiencia cotidiana, como queriendo decirnos que es a partir de los lugares más mundanos -sean humanos o inhumanos- donde comienza la exigente tarea que tiene asignada toda filosofía (también en el terreno de la educación): la elaboración del concepto.

Por supuesto, el trabajo conceptual es un trabajo teórico por excelencia. Pero más allá de las disputas epistemológicas en torno a lo que vale en educación como teoría o no, lo que interesa subrayar ahora es algo más concreto, y en cierto modo relacionado con lo anterior. Pues un trabajo de "teoría", se concrete en un campo como la filosofía de la educación o en otro diferente de las ciencias humanas, es algo parecido al ejercicio de reordenación de una biblioteca, de una serie de lecturas: "Colocar unos textos junto a otros, con los que aparentemente no tienen nada que ver y producir así un nuevo efecto de sentido" (Larrosa, 1995, 259). Es así que en este trabajo de colocar unos textos junto a otros, o frente a otros, o contra otros, el pensar (en educación) surge como una verdadera experiencia, un ejercicio o un ensayo (del pensamiento).

\section{LA "IMPOSTURA PEDAGÓGICA" O ACERCA DE UNA PEDAGOGÍA POSTEDUCATIVA}

Se aprende, o se puede aprender algo, cuando se estudia un libro del mismo modo que cuando estamos ante una manifestación artística -música, pintura, literatura, cine-, paseamos por la ciudad o nos enfrentamos, como investigadores de la educación, al estudio de una parcela de la realidad con el objeto de resolver un problema o una cuestión determinada. Se aprende o se puede aprender. Hay, en todos estos encuentros, una potencia de aprendizaje. No es una cuestión de estar más informados después en relación con un antes, pues de hecho ocurre que podemos volver a aprender lo que ya sabíamos, o creíamos saber, siempre que algo nuevo nos sucede y caemos en la cuenta. En realidad, uno nunca sabe cómo, en el aprender algo, se pasa del antes al después, de la potencia al acto, de la ignorancia al saber. En el aprender no se pasa, en realidad, de lo posible a lo real, sino, más bien, de lo 
imposible a lo verdadero. En el aprender estamos, de hecho, entre un saber que ya disponemos y un no saber que nos falta. Pero parece que todo nos empuja a tener que estar más cerca de la articulación del conocimiento que de la articulación de nuestra ignorancia. Nos falta un informe sobre nuestras ignorancias.

Más que un ejercicio lineal y previsible, por tanto, el aprender es discontinuo, una actividad en devenir, incompleta, algo más importante, en el fondo, que lo que culmina en la adquisición de un saber. En cierta medida, el aprender queda disuelto -desaparece- en el saber: el aprendiz, todo aprendiz, es un sujeto de la experiencia en parte encadenado a un no saber; es amigo de una ciencia todavía confusa, de un asombro esencial. Hay aquí algo extraño y paradójico, que todo saber pedagogista, seguro de su pretendida potencia, y ciego a su impotencia, desconoce: el que sabe algo (el que ha aprendido, el poeta, el músico, el bailarín, el pintor) "no saben lo que hacen ni lo que dicen, pero saben hacerlo y decirlo a la perfección" (Pardo, 2004, 33); por eso, para aprender cualquiera de estas artes, un aprendiz debe dejarse tutelar por cada uno de estos maestros, porque ellos han aprendido a estar, armónicamente posicionados, entre lo que saben y lo que no alcanzan y todavía ignoran. No hay otra salida: a bailar se aprende bailando. Y para ello se requiere de todo lo que nuestra sociedad, democrática y de aprendizaje, carece: saber habitar nuestra espera, entre el antes y el después, entre la potencia y el acto, entre la potencia y la impotencia, entre el comienzo y el final: "¿Cómo sería posible aprender en un mundo que constantemente nos abandona, arrastrando todo cuanto queremos y a nosotros mismos en la corriente, sin dejarnos acabar nada de lo que habíamos empezado?" (Pardo, 2004, 53).

En todo caso, en el aprender prestamos atención a lo que no habíamos previsto, hacia algo que cambió nuestra ruta y una dirección previamente marcada. Lo que parecía imposible devino posibilidad y potencia. Que ello sea así se debe a que un acontecimiento nos ha sobrevenido. Según Gilles Deleuze, el acontecimiento no es tanto el qué de lo que sucede como lo que ocurre desde el impacto de lo sorprendente y no planificado, de lo imprevisto; algo así como lo que se hace presente y exige ser asumido, comprendido o representado en lo que nos sucede. En su libro Lógica del sentido señala Deleuze que la realidad está constituida por dos tipos de elementos: "cosas y estado de cosas" (cuerpos) y "acontecimientos" (o incorporales) (Deleuze, 2005, 52). El tiempo de las cosas -donde el hombre se instala, vive y aprende- es el presente; las cosas están en el espacio, y los acontecimientos -que son incorporales-, más que existir, insisten en las cosas y en los estados de las cosas. Se efectúan en ellos, y su tiempo es el del devenir. Los acontecimientos, pues, nos afectan. En ellos está "eso que nos pasa". En ellos, por ellos, hacemos experiencia y su temporalidad es intensiva. En el régimen del acontecimiento parece que se nos impone un cierto tipo de relación: con el mundo y con nosotros mismos. No tenemos más remedio que estar a la altura de aquello que nos acontece; hacernos hijos de nuestros acontecimientos, dice Deleuze, y desde ellos "renacer". Si esto es así, entonces el acontecimiento es, también, la experiencia de una presencia. 
Si ponemos en relación esta caracterización del acontecimiento con lo que pasa cuando aprendemos, diremos, también con Deleuze, que, por su mismo carácter inanticipable, "nunca se sabe por anticipado cómo alguien va a aprender: por qué amores se llega a ser bueno en latín, por qué encuentros se es filósofo, en qué diccionarios se aprende a pensar" (Deleuze, 1968, 215). Aprender no es sino el mediador entre un no saber y un saber, un paso viviente de uno a otro, que requiere la máxima atención. Pero ese pasaje del no saber al saber -y aquí hay una clave importante- está repleto de azares e imprevistos, de casualidades e incertidumbres. Es un pasaje que tiene algo de poético, pues es propio del poeta hacer pasar algo del no ser al ser. Aprender tiene que ver con la creación o producción de una presencia, la que a cada uno le corresponde al aprender a estar y habitar.

Las anteriores consideraciones han pretendido plantear un análisis filosófico de la educación (y de su investigación) como algo vinculado a las nociones de experiencia y acontecimiento. Soy consciente de que articular una concepción de la filosofía de la educación en una noción tan difusa y ambivalente en el vocabulario filosófico como la de experiencia es un riesgo. A pesar de todo, creo que tiene sus ventajas y ofrece también nuevas posibilidades. Una de ellas es que nos proporciona recursos para una crítica del pedagogismo, una actitud que no le hace mucho bien a la mejor tradición intelectual y académica de los estudios pedagógicos, que tiene fuertes vínculos con el mejor pensamiento filosófico, estético y literario. En este sentido, las críticas a cierto pedagogismo rampante en el mundo académico contemporáneo deberían sostenerse sobre la base de, como mínimo, una distinción entre dos modos de entender la noción de pedagogía (Stal, 2008, 28-34).

Según la primera acepción, la pedagogía designaría, en un sentido adjetivo, las cualidades del buen maestro capaz de transmitir lo que sabe con claridad y exactitud, suscitando la pasión y el interés de su auditorio. En este sentido, la pedagogía es un talento, cierto arte que la experiencia permite desarrollar "hasta cierto punto" y que reposa en recursos psicológicos y de otra índole más o menos ocultos que no se pueden desvelar fácilmente y, a fortiori, movilizar a voluntad. Aquí, la transmisión de los saberes no equivale a las condiciones técnicas de su transmisión. Así, algunas personas, que no son pedagogos profesionales, de hecho, lo son por naturaleza; y a la inversa también puede ocurrir. Por eso no es preciso ser un sabio para lograr ser un buen pedagogo. Y, tal vez por ello mismo, cabría suponer que quien domina un ámbito de conocimiento puede volver superfluo el recurso a cierta pedagogía que se confunde con la aplicación de una serie de técnicas o tecnologías. O dicho en otros términos: la pedagogía, más que un fin en sí, encuentra su razón de ser en el saber que ella misma debería facilitar asimilar en el aprendiz. No podría ser el objeto de una ciencia, puesto que toda ciencia realmente adquirida volvería superfluas las pretensiones de una "ciencia pedagógica" en un sentido técnico pretendidamente muy especializado. Su uso más legítimo, entonces, se encontraría en una especie de tiempo intermedio donde el aprendiz aprende a base de las explicaciones de las que tiene necesidad para comprender aquello que ha de adquirir. 
El segundo empleo del término pedagogía es substantivo: aquí lo que se exige no es ese talento más o menos innato, sino un conjunto de conocimientos y competencias técnicas, unos saberes profesionales, porque se supone que el conocimiento de la cultura no es lo mismo que la cultura como objeto de conocimiento y transmisión pedagógica. En este caso, la cuestión está en saber si la pedagogía, así definida, se convierte en una especie de principio de distinción que permite distinguir los "viejos maestros" de los "modernos". Lo que interesa descubrir en esta distinción es no tanto ciertas razones para proceder a un ataque indiscriminado de la pedagogía, sino los argumentos que nos permitan analizar con cierta calma y la mayor lucidez posible determinada impostura pedagógica, que personalmente creo que no es buena para la pedagogía; aquella que consiste en afirmar que la razón de ser de la escuela ya no es la adquisición de conocimientos y la transmisión de determinados saberes -la transmisión de mundo a través de la necesaria mediación de la cultura-, sino cosas tales como la previsión de la acción pedagógica, el desarrollo de estrategias de aprendizaje, las actividades de evaluación, la gestión de grupos, el análisis de las prácticas, que serían los objetivos fundamentales de un aula escolar.

Este didactismo, por así denominarlo, genera lo que podríamos llamar una pedagogía posteducativa que reclama para sí la tarea de descomponer las operaciones del pensamiento en la serie de bits o de ítems que componen un kit pedagógico perfectamente disponible para su inmediata utilización. De acuerdo con tal pretensión, puesto que sabemos que leemos en nuestra lengua de izquierda a derecha no se hablará de otra cosa que de lateralizar a los niños, lateralización que constituiría un prerrequisito indispensable del aprendizaje de la lectura; del mismo modo, ya que siempre escribimos con algún tipo de útil o instrumento, asegurarse de que los niños de tres años dominen el gesto gráfico y que desarrollen su motricidad fina sería la tarea central de un buen trabajo pedagógico con ellos para lograr que aprendan a escribir correctamente. Lo que quiero señalar con estos sencillos ejemplos es hasta qué punto esta impostura pedagógica daña el buen sentido de una auténtica pedagogía que, aunque no sepamos dónde se encuentra, insistimos en perseguir y tratamos de pensar con nuestras mejores armas y buena disposición.

El filósofo de la educación holandés Max van Manen dice algo al respecto que es muy pertinente recordar aquí:

La pedagogía no es algo que pueda ser "tenido", "poseído", en el sentido en que podemos decir que una persona "tiene" $\mathrm{O}$ "posee" un conjunto de habilidades específicas o competencias de actuación, sino que la pedagogía es algo que un padre o un profesor debe continuamente cumplir, recuperar, recobrar, volver a capturar, en el sentido de recordar. Cada situación en la que actúo educacionalmente con niños requiere que yo sea sensible de un modo continuo y reflexivo a aquello que me autoriza en tanto que profesor o padre. Justamente porque la pedagogía es, en un sentido último y definitivo, insondable, plantea una invitación incansable a la actividad creativa de la reflexión pedagógica que hace salir a la luz el significado profundo de la pedagogía (Manen, 2003, 164-165). 
UNA PEDAGOGÍA DE LA PRESENCIA. CRÍTICA FILOSÓFICA DE LA IMPOSTURA PEDAGÓGICA

El núcleo de lo pedagógico es algo que podemos llegar a captar, y no siempre sin llegar a concretar muy bien cómo. En sus reflexiones sobre estos asuntos, Manen formula una idea no sin cierta perplejidad, como quien dice algo que todo el mundo debería saber pero ha olvidado. Lo que formula Manen, muy en su estilo, tiene como referencia última una serie de "anécdotas" de la vida diaria, situaciones que o bien en alguna ocasión hemos vivido o hemos conocido por otros. Manen insiste en preguntarse por qué cuanto más creemos haber cercado conceptualmente el núcleo de lo pedagógico, más se nos escapa, porque ese núcleo no consiste ni en producir en otro una serie de conductas observables ni en saber aplicar una serie de reglas o principios derivados de las teorías educativas ni en saber formular intelectualmente bien determinados temas educativos. Manen probablemente es consciente de que lo que está a punto de decir podría ser interpretado como un gesto moralista, pero aun así expresa su pensamiento en forma de pregunta:

¿Por qué será que hay tanta gente que se preocupa a diario de los entresijos de la teoría educacional y parece tan sorprendentemente incompetente y despreocupada a la vez? ¿Significa que lo que decimos sobre los niños no encuentra su reverberación en la vida vivida, que convivir con los niños es una cosa y hablar sobre cómo debemos convivir con ellos es otra? ¿Qué importancia tiene, entonces, teorizar y crear un pensamiento investigador y académico si no conecta en absoluto con las prácticas reales de la vida cotidiana? (Manen, 2003, 163-164).

Lo que Manen se pregunta tiene que ver con el modo como nos tomamos o no en serio eso que estudiamos, eso que pensamos o eso a propósito de lo cual teorizamos y que llamamos educación. Pero tomarse en serio la educación no es amar más un concepto, y ni siquiera tiene que ver con embellecer más nuestros discursos o nuestra escritura pedagógica, como quien busca l'art pour l'art. Tiene que ver con tomarse en serio al otro, un ser singular, que tenemos delante, y que es una novedad del mundo.

Este pedagogismo al que me estoy refiriendo da la impresión de que sustituye el conocimiento, la reflexión, el esfuerzo por cierta dignidad en la transmisión de los saberes, en fin, la experiencia misma de proponer cierto tipo de relación con la cultura y los textos que la componen, por una especie de saber-hacer, por el empeño en la adquisición de una serie de competencias desconectadas y separadas de una experiencia educativa y formativa, por la manipulación de informaciones ante las cuales, en principio, todos somos iguales, según el código de una democracia perfectamente democratizada. Es como si pretendiésemos educar sin instruir, sin enseñar, sin transmitir, y sin poner a disposición de nuestros alumnos lo mejor que la cultura ha elaborado favoreciendo relaciones maduras con sus productos: con sus textos, sus obras de arte, su ciencia, en definitiva, sus saberes. Es como si la acción pedagógica sólo pudiese ser tal resolviéndose en mera, pura y simple relación entre profesores y alumnos, educadores y educandos, pero sin la exigente mediación de un objeto (un saber, un libro, un texto), que es donde reside toda la autoridad. Un objeto externo a la relación, para que la relación 
pedagógica no devenga algo cuya razón de ser reside en ella misma, en su gestión, administración, tecnificación y pedagogización. Una pedagogía que se resuelve, en fin, en la manipulación y dominio de sus procedimientos técnicos.

André Comte-Sponville señaló en un texto de 1984 titulado "Sur l'enseignement de la philosophie", recogido después en su libro Une éducation philosophique, que "el pedagogismo consiste en privilegiar la educación en detrimento de la instrucción, hasta el punto de disolver todo contenido y todo saber en beneficio de una pedagogía general" (Comte-Sponville, 1989, 113-114). Este pedagogismo, así formulado, es el vehículo de un número de fuerzas -ideológicas, profesionales, sindicales- internas al entorno de los profesores (el caso francés, al que él especialmente se refiere, es muy emblemático). El meollo del problema aquí, según la interpretación de este autor, es la existencia de cierto progresismo pedagógico que a fuerza de querer que la escuela sea liberadora, no tanto del individuo, sino de la sociedad, obliga siempre a ambicionar ciertos futuros, a avanzar por encima del paso del propio tiempo, sacrificando de esta suerte la conservación y la transmisión del pasado.

El lema del progresismo pedagógico es más o menos que la función y tarea de la escuela es "enseñar a vivir". Este aprendizaje de la vida adquiere, en el contexto de la sociedad de aprendizaje, connotaciones y consecuencias muy específicas. El lema del discurso de la sociedad de aprendizaje es, como se sabe, "aprender a aprender" (o "aprendizaje para toda la vida"), eslogan que coloca al sujeto y al ciudadano en la situación de una especie de eterno aprendiz. La categoría central del discurso de la sociedad de aprendizaje es, por supuesto, la de aprendizaje, quedando obsoleta la cuestión referida a la enseñanza. Sólo existe el discurso discente. Puede decirse que la supervivencia real y efectiva, desde el punto de vista social, del ciudadano depende de su capacidad de asumir los retos que el mentado lema enuncia -aprender a aprender-, con lo que, de hecho, su vida presenta la lógica inherente de la nuda vida, esto es, la vida del animal laborans, de una vida meramente biológica destinada a sobrevivirse (Masschelein, 2001; Storme y Vlieghe, 2011).

La figura del aprendiz eterno (Bárcena, 2012) expresa a la perfección la racionalidad de la biopolítica moderna -cuya manifestación en la educación haría de ella una pedagogía biopolítica-, en la línea sugerida por Foucault en los siguientes términos: "Durante milenios, el hombre siguió siendo lo que era para Aristóteles: un animal viviente y además capaz de una existencia política; el hombre moderno es un animal en cuya política está puesta en entredicho su vida de ser viviente" (Foucault, 2003, 173). La biopolítica hace uso de cualquier sistema o subsistema social - por ejemplo, el sistema educativo- para administrar, gestionar y normalizar las vidas de los ciudadanos en un marco cuyos valores centrales serán la seguridad, el orden, la jerarquía, la clasificación, la métrica, la cuadrícula. En este contexto, la idea de la educación como formación (Bildung), o como Paideia, el sentido de la educación como acontecimiento o como experiencia -algo que le pasa al 
que aprende en el seno de un encuentro educativo asimétrico- queda literalmente excluida del discurso pedagógico.

Sánchez Ferlosio expresaba muy gráficamente una deriva de esta lógica de la pedagogía biopolítica: "La escuela de hoy se ofrece a las familias a manera de "plan personalizado" o de "especialistas en ti" ". Un alumno permanentemente en curso -siempre alumno-, gestor de su propia condición y de su saber. La voz "autonomía" sirve entonces, disculpada ya de tener que razonarse o profundizarse o explicarse mejor filosóficamente, como emblema de esta nueva filosofía: algunas normativas curriculares prescriben, por ejemplo, como competencia para los alumnos la "autonomía y la iniciativa personales". Hasta donde este propósito requiera el desarrollo de cierta individualidad, la misma es algo susceptible de ser gestionada, pero no experimentada. No es una experiencia, sino una competencia (Jódar, 2007, 165-187).

Esta figura hace que el alumno sea, de hecho, pretendiendo liberarle y emanciparle, un sujeto perfectamente infantilizado y normalizado. Según esta concepción, afirmar que la escuela -o mejor aún, la educación- tiene una función protectora o conservadora -la conservación de un mundo que se transmite en un encuentro entre generaciones en la filiación y la discontinuidad del tiempo-, y que no puede pretender sustituir a la acción política ni cambiar una sociedad mediante normatividades jurídicas, se recibe en términos de puro conservadurismo. Y es así, siempre dentro de la lógica del progresismo pedagógico, porque aquí hay una notable confusión de órdenes: el orden del poder y el orden del saber, el orden político y el orden pedagógico, la autoridad política y la autoridad pedagógica, que es una categoría temporal, no espacial.

Por tanto, del mismo modo que hay que salvar a la pedagogía -como práctica y como saber- del pedagogismo -entendido como doctrina o como ideología-, es preciso salvar la conservación -la transmisión del mundo a través de la cultura y los saberes en la escuela- del conservadurismo (político). Por los mismos motivos, hay que intentar proteger a la filosofía de todo filosofismo, o quizá mejor: el amor a la filosofía del amor al discurso. Del mismo modo que la filosofía puede ser protegida mejor por filósofos y pensadores que por impostores, sofistas o falsos maestros que lo único que buscan es hacer escuela de acólitos obedientes incapaces de caminar por sí mismos sin consultar a cada paso el índice analítico de las obras completas de sus maestros, la pedagogía quizá la puedan proteger mejor los verdaderos pedagogos, aquellos que, renunciando a todo paternalismo y progresía políticamente correctas, y a todo moralismo, simplemente busquen, pero no a cualquier precio, ayudar a que el aprendiz esté en disposición de madurar aprendiendo a celebrar su infancia despidiéndola con dignidad.

Creo, sinceramente, que una filosofía de la educación capaz de volver a pensar la educación como una experiencia puede contribuir a una pedagogía capaz de no perder el sentido común al mismo tiempo que está atenta a los acontecimientos y retos del presente. Al autor de estas páginas le gustaría pensar que lo que acaba de escribir se entiende en sus justos términos. Dicho más contundentemente: no 
deseo acusar, ni criticar, ni poner cerco alguno a la pedagogía, parte de cuyas fuentes son la filosofía, la antropología, la literatura, sino contribuir a reflexionar sobre las consecuencias de la impostura pedagógica fomentadas por determinado didactismo, que ni siquiera ha sido capaz de respetar la historia más excelente de la propia disciplina de la didáctica, y que al extenderse consolidan la lógica de una pedagogía biopolítica.

Esta impostura pedagógica parece fundada en un reconocimiento y en una especie de mito. El reconocimiento es la concepción del niño como "estudiante", como "escolar", una figura que necesita ser pensada como sujeto precario. El aprendizaje es definido aquí, siempre, como carencia (Biesta, 2011). El niño, en tanto que estudiante, en tanto que sujeto que aprende, es un sujeto frágil, incompleto, precario, en el que hay que producir aquello que la pedagogía, así entendida, posee. Es el instrumento que el pedagogismo usa para legitimarse a sí mismo, la vía que explica cómo ese niño-estudiante-escolar pasa de su precariedad a su ser completo, de su ignorancia al saber y a la ciencia. Es la que cuenta con los instrumentos para que el sujeto que aprende pase de la voz al logos, de un "todavía-no" al "ya-no". Ese "todavía-no" el discurso pedagogista lo piensa como el comienzo de todo: el niño, que es ignorante y aún no habla, debe ser preparado, adiestrado para que lo haga. "Todavía-no": todavía no has llegado al punto final, todavía no has comprendido, todavía no estás preparado, aún te falta tiempo. El "ya-no" es el final del proceso, del recorrido educativo, un final que el saber pedagogista anticipa en términos de competencias definidas a priori.

Pero también he señalado que hay un mito fundador, inaugural, del pedagogismo. Una especie de ilusión que funda su quehacer y sus propósitos, toda su trama. Este mito consiste en la lógica explicatoria, en su necesidad, en el hecho de que para que alguien aprenda es necesario que se le explique algo en una relación unidireccional que se basta a sí misma y no remite a nada que sea externo a ella. Este mito inaugural sostiene que la explicación es necesaria para que se produzca un aprendizaje, que el aprender depende de que un profesor explique lo que no entendemos. Que no se puede producir aprendizaje en otro desde la "ignorancia". La necesidad de la explicación es paralela a la exigencia de la comprensión, comprensión que no se produciría sin aquélla. Según esto, el saber pedagogista tiene la obligación de adaptarse a los jóvenes a quienes se dirige, adaptarse a costa de su objeto, al que puede llegar a trivializar, de modo que este saber dicta que, para que se den la comprensión y el aprendizaje, hay que pasar de lo más simple a lo más complejo. Hay que someter la (falta) de inteligencia del alumno a la inteligencia del enseñante, ligar la una a la otra.

\section{Pedagogía de la PRESENCIA EN El APRENDER: DE la EMANCIPACión INTELECTUAL}

Jacques Rancière ha expuesto en El maestro ignorante interesantes argumentos sobre este pedagogismo. El libro de Rancière tiene su base histórica en la aventura intelectual que en 1818 Joseph Jacotot, lector de literatura francesa en la Universidad de 
Lovaina, realizó con alumnos en los Países Bajos, adonde le llevó el exilio. Teniendo que enseñar a alumnos que desconocían el francés, como él mismo desconocía el holandés, el azar decidió su proceder. Como no existía entre ellos cosa alguna común, y al haberse publicado por esas fechas en edición bilingüe Las aventuras de Telémaco, de Fénelon, hizo enviar el libro a sus alumnos a través de un intérprete pidiéndoles que aprendieran el texto francés ayudándose de la traducción. A medida que avanzaban en la lectura les hacía repetir una y otra vez lo que habían aprendido diciéndoles que se contentasen con leer como pudiesen la segunda parte del libro al menos para poderlo contar. El proceder de Jacotot consistió en considerar que no hay un punto de partida del saber, sino que lo que hay que hacer es continuar un camino ya comenzado. Su método consistió en darse cuenta de que un "método" no es un conjunto de procedimientos y técnicas, sino una manera de marchar, de caminar, de habitar un espacio y transitar un recorrido. Un viaje. Recordemos que educación, que también viene de la palabra latina educere, significa salir afuera, es decir, viajar. A cada paso es el sentido de la marcha lo que cuenta. Prestar atención a cada momento del camino, preguntarse: ¿y yo qué veo?, ¿y yo qué pienso? Así, dice Jacotot en Langue maternelle: "Pienso que todo hombre es un animal razonable, capaz por consiguiente de captar relaciones. Cuando el hombre quiere instruirse, es preciso que compare las cosas que conoce entre sí y que las compare con las que aún no conoce" (Jacotot, 2008, 25).

Lo que Rancière defiende, recuperando esta aventura pedagógica, es que "la explicación no es necesaria para remediar una incapacidad de comprensión. Todo lo contrario, esta incapacidad es la ficción que estructura la concepción explicadora del mundo" (Rancière, 1987, 15). Para Rancière, lo decisivo no está en el saber del enseñante, entendido como un cuerpo de información supuestamente disponible para ser comunicado de un lugar a otro. Lo decisivo está en otro lugar: está en la manera en que el profesor se acerca a su objeto; en el modo en el que se hace presente ante él y en la relación que ayuda a estructurar con y junto el alumno; en la relación de éste con ese objeto que media entre ambos. Lo decisivo no está en someter la inteligencia del alumno a la suya, sino en liberar la inteligencia del alumno forzándole a que no pierda de vista su objeto. A que siga pensando, a que preste atención, a que concentre su mirada. Se trata de darle confianza: no te desvies de tu ruta, insiste, piensa, di qué piensas, mantente en la ruta trazada. Se trata de estar presente en la relación de un modo que se evite el principio del atontamiento pedagógico, del debilitamiento y de la fragilización del aprendiz, al que a costa de querer "emanciparlo" llevándole al saber, se le estupidiza e infantiliza, alumnizándole.

En el contexto de la Universidad española actual, por lo menos para muchas Facultades de Educación, la última reforma educativa de la enseñanza superior corre el riesgo de producir un efecto de una importante "secundarización" de los estudios educativos y, en este sentido, las recomendaciones de Rancière pueden resultar un verdadero revulsivo pedagógico; nos haría "Vomitar", valga esta imagen, algunas cosas que no nos están haciendo mucho bien por dentro, siendo su efecto claramente sanador. Las relaciones entre profesores y alumnos, a la hora de dar 
a leer a nuestros alumnos algunos textos, están presididas por la desconfianza. Seguimos creyendo que existe una desigualdad de las inteligencias, y que el único modo para hacer que los alumnos comprendan lo que leen es el de interpretarles lo que de hecho ya han leído -sometiendo su inferior inteligencia a la nuestra superior-, y de explicárselo a base de fichas-guías, porque, así se piensa, todavía no están preparados para ejercer una lectura adulta del texto. Frente a esta creencia, es de lo más recomendable hacer caso del siguiente consejo de Sánchez Ferlosio: "¿Acaso no sería mejor entrada, mejor iniciación, pregunto entonces, irrumpir sin más y a cuerpo limpio en el corazón del libro y penetrar en un único capítulo, haciendo presa en la materia misma, sin arredrarse ante las dificultades y demorándose en ella hasta entenderla?» (Sánchez Ferlosio, 2002, 48).

Así pues, una enseñanza y una relación pedagógica más emancipadora consistirían en afirmar que entre el maestro y el aprendiz existe esa tercera cosa, un tercer elemento -un libro, un texto, un objeto de aprendizaje- que es extranjero tanto a uno como a otro y al cual ambos deben constantemente referirse para verificar en común lo que el alumno ha visto, lo que dice y lo que piensa: "Es esta tercera cosa de la que ninguno es propietario, ante la cual ninguno de los dos posee el sentido, la que se tiende entre ellos" (Rancière, 1987, 19). Esta lógica contradice la lógica del saber pedagogista, que sostiene que lo que el alumno debe aprender es lo que el profesor le enseña, o sea, que lo que el alumno, como espectador, debe ver es lo que el profesor, en la escena pedagógicamente diseñada, le hace ver: porque ya lo ha visto (y debe haberlo visto de hecho) antes que él. Dicho así creo que se entiende que la enseñanza libera, y esta liberación, de hecho, comienza cuando se comprende que mirar, ser espectador, es también un tipo de acción, una experiencia que transforma.

Todo pasa, entonces, por la idea de que "conocer" significa tener que adaptarse -lo cual, sin duda, requiere esfuerzo- al rigor de aquello que se trata de conocer y que en consecuencia resulta como mínimo superfluo cualquier intento de adaptar los conocimientos al discente, sea en sentido individual o colectivo, en sentido psicológico o sociológico. Porque "no es posible aprender sin aprender algo" (Pardo, 2004, 28). Es en este sentido en el que tal vez habría que tomar precauciones con respecto a esa actitud excesivamente escolar, en un sentido rebajado del término, que pretende que los conocimientos carecen de su propio rigor y que se dejan utilizar para hacer de ellos una especie de amalgama más o menos adaptada a las necesidades de cada cual. Es este tipo de cóctel el que favorece el tipo de escolar normalizado, permanentemente aprendiz y no emancipado. El alumno, actuando, hace experiencia de aprendizaje observando, seleccionando, comparando, interpretando, traduciendo lo que ve con algo que le es externo, un objeto, un saber, un texto. De acuerdo con este principio, lo que el maestro enseña no es, propiamente, su saber explicándolo, como queriendo anular la distancia existente entre su saber docente y la ignorancia del aprendiz, sino que, por así decir, le manda que se adentre en el bosque, que cuente lo que ve, lo que piensa de lo que ha visto, que compruebe sus afirmaciones. Que salga afuera-educere-, 
que se exponga, que se haga presente en esa salida, en eso que ve, en ese saber, en ese tercer elemento que es la necesaria mediación en una relación educativa.

Rancière se ha referido también a la "paradoja del espectador", que se puede formular en estos términos:

Ser espectador es un mal, y ello por dos razones. En primer lugar, mirar es lo contrario de conocer. El espectador permanece ante una apariencia, ignorando el proceso de producción de esa apariencia o la realidad que ella recubre. En segundo lugar, es lo contrario de actuar. El espectador permanece inmóvil en su sitio, pasivo. Ser espectador es estar separado al mismo tiempo de la capacidad de conocer y del poder de actuar (Rancière, 2008, 8).

Entre actores y espectadores existe una distancia parecida a la que se supone que existe entre maestros y aprendices, entre profesores y alumnos. Y la lógica inmanente a estas relaciones supone que esta distancia debe eliminarse para que espectadores (o aprendices y alumnos), que son pasivos, comprendan (o aprendan). Ahora bien: cuanto más se quiere suprimir esa distancia más necesidad existe de explicarla, introduciendo nuevos saberes que, paradójicamente, la incrementan. Según esta lógica, la condición de espectador-pasivo no contiene momento de experiencia alguno. Y es aquí donde se plantea, entonces, la posibilidad de invertir los términos del problema y preguntarse si no es justamente la voluntad de suprimir la distancia la que la aumenta todavía más. Como dice Rancière:

¿Qué es lo que permite considerar como inactivo al espectador sentado en su asiento, si no es la radical oposición previamente aceptada entre lo activo y lo pasivo? ¿Por qué identificar mirada y pasividad, si no es por el presupuesto de que mirar quiere decir complacerse en la imagen y en la apariencia, ignorando la verdad que está detrás de la imagen y la realidad fuera del teatro? ¿Por qué asimilar escucha y pasividad, si no es por el prejuicio de que la palabra es lo contrario de la acción? (Rancière, 2008, 18).

Este tipo de oposiciones - mirar/saber, apariencia/realidad, actividad/pasividad- definen un reparto de lo sensible, una distribución a priori de las posiciones de los sujetos en el escenario de la actividad y de las capacidades e incapacidades ligadas a dichas posiciones. Son, dice Rancière, alegorías encarnadas de la desigualdad (los que poseen una capacidad y los que carecen de ella), y de este modo se descalifica al espectador porque no hace nada mientras que los actores, en el escenario, o los trabajadores afuera ponen el cuerpo en acción.

Ahora bien, cuando problematizamos estas relaciones de oposición y cuestionamos la hostilidad entre mirar y actuar, entonces entendemos de inmediato que mirar es también una acción que confirma o que transforma esa distribución de las posiciones. El espectador también actúa, como el alumno o como el hombre ilustrado y docto: hace una experiencia observando, seleccionando, comparando, interpretando, traduciendo signos que se despliegan en lo heterogéneo. Dejándose afectar y siendo activo en esa afectación. Se convierte en un ser pasible. Esta 
condición implica ser activos en el modo de recibir lo que nos pasa, una forma de presencia en el acontecimiento. Como sujeto de la experiencia, el sujeto pasible, por decirlo así, traduce la lengua que escucha, y los signos que percibe, en una voz propia, y al proceder así compone su propio poema con los elementos del poema que tiene delante. Hace todo esto haciéndose presente en su propio presente, en la realidad en la que está. Construye su propio poema. Y es ahí donde el enseñar y el aprender, la experiencia, en suma de la educación, enuncia su propia poética. Una poética de la educación.

Ningún aprendizaje, entonces, evita el viaje, la salida hacia el afuera:

Bajo la orientación de un guía, la educación empuja hacia el exterior. Parte: sal. Sal del vientre de tu madre, de la cuna, de la sombra de la casa paterna y de los paisajes juveniles. Al viento y a la lluvia: ahí afuera, faltan todos los abrigos. Tus ideas iniciales no repiten sino palabras antiguas. Joven: viejo parlanchín. El viaje de los hijos tiene el sentido desnudo de la palabra griega pedagogía. Aprender provoca la salida (Serres, 1993, 23).

Salir, partir, es dejarse seducir. Seducere significa llevar a la mujer a la casa propia, que es un lugar privado. Siempre hemos creído que la seducción era eso lo que implicaba: aplicar ciertas artes de persuasión para llevar a alguien a un espacio privado, oculto a miradas indiscretas. Pero podemos leer pedagógicamente esta palabra -seducere- en relación con el salir afuera del educere de otro modo: (s)educere sería entonces llevar a alguien no sólo al espacio de su propia privacidad, al lugar que le es propio, para que se haga presente en él, sino llevarlo, o mejor, acompañarlo, hacia un lugar público, al espacio de pluralidad donde aparecemos -nos hacemos presentes- ante todos los demás. De nuevo Serres es exacto aquí: «Dejarse seducir. Volverse varios, enfrentar el exterior, caminar en cualquier dirección [...] Porque no existe aprendizaje sin exposición, muchas veces peligrosa, a lo otro. Jamás sabré lo que soy, dónde estoy, de dónde vengo, para dónde voy, por dónde avanzar. Me expongo a los otros, a las singularidades" (Serres, 1993, 24). Así, el juego de la pedagogía no se efectúa a dos bandas, el viajero y su destino, sino a tres: el tercer lugar interviene ahí tanto como el límite del paisaje. Sin embargo, ni el aprendiz ni el iniciador saben muchas veces cuál es el lugar de esa puerta de entrada al tercer elemento -el tercero instruido-, ni tampoco su uso exacto. Un día, en cualquier momento, algo pasa: acontece. Atravesamos la senda, cruzamos el río o el bosque, y todo queda finalmente comprendido.

Las ideas de Rancière y su "exhumación de Jacotot" -como señala Alejandro Cerletti (2008) - se ponen al servicio de una relación pedagógica cuyo fin es la verdadera emancipación intelectual del alumno, no su sometimiento a partir del establecimiento del principio de la desigualdad de las inteligencias y la disponibilidad adaptable de los saberes. Sólo se llega a la igualdad desde la misma experiencia de una igualdad, como sólo se aprende la libertad desde la misma experiencia de su ejercicio. Es un ejercicio que pone en cuestión todo un sistema y una política de las transmisiones educativas inscrita a fuego en nuestras instituciones educativas, la Universidad incluida. 
UNA PEDAGOGÍA DE LA PRESENCIA. CRÍTICA FILOSÓFICA DE LA IMPOSTURA PEDAGÓGICA

Poner en cuestión este principio que divide el mundo en dos -los que saben y los que no saben- no significa de ningún modo aceptar como saber cualquier tipo de ignorancia. Del mismo modo, aprender sin un "maestro explicador" no quiere decir que se tenga que prescindir de todo maestro y sin la mediación de una relación educativa solvente. No se trata de sustituir la falta de igualdad por un igualitarismo que empeoraría aún más las cosas. Significa afirmar que lo que en realidad se enseña, cuando se busca ayudar a la emancipación intelectual de otro, es a usar la propia inteligencia, no a someterla; la enseñanza está destinada a que el otro sepa utilizarse a si mismo lo mejor posible, y no solamente a utilizar lo que le han enseñado. La función del profesor, entonces, no es sino plantear al alumno un desafío del que, en realidad, no podrá salir más que por sí mismo. Se trata de interrogarlo como a un igual y no como un conocedor que ya sabe todas las respuestas. Aquí, el maestro sabe que él también está aprendiendo de modo que las respuestas del alumno son también nuevas preguntas para él: acontecimientos del pensamiento: "La palabra circula entre todos y no en una sola dirección" (Cerletti, 2008, 302).

El panorama actual del mundo escolar, y en especial del universitario, ha cambiado de tal modo que ya no es fácil pensar la transmisión de los saberes y las disciplinas en los términos que sugieren estas reflexiones. No se trata de hacer de ninguna propuesta un modelo a aplicar linealmente, sino de servirnos de sus intuiciones más valiosas para pensar una pedagogía de la transmisión de otro modo. En este sentido, ya sé que no digo nada nuevo si afirmo que el actual modelo universitario responde, en esencia, a la estructura misma de lo que se ha dado en llamar "Sociedad del conocimiento", uno de cuyos defensores es, como se sabe, Anthony Giddens -y es sintomático al respecto que el organismo de su país encargado de gestionar y administrar la instrucción pública pasase de denominarse "Ministerio de Educación y Ciencia" a "Ministerio de Educación y habilidades (skills)"- que en un artículo del año 2006 decía: "En las actuales economías avanzadas, más del $80 \%$ de la mano de obra trabaja en los sectores de producción de conocimientos" (Giddens, 2006).

Como ha señalado José Luis Pardo, cuyos argumentos sigo aquí, la cuestión a destacar aquí no es si el porcentaje más elevado de los empleados actualmente activos en nuestras sociedades son doctores, licenciados o titulados superiores -que en su mayoría seguramente no lo son-, sino que tanto tales figuras como otras no universitarias, gracias a las artes de la mentada sociedad del conocimiento, se han igualado a través de uno de los eslóganes centrales de este modelo: la lifelong education. Y esto es algo bien expresivo en el fondo: "Pues solamente una mano de obra perfectamente descualificada necesita una permanente recualificación" (Pardo, 2010, 265). Y ésa es la contradicción. También sé que una cosa es lo que señalen en términos de imperativo jurídico las normativas legales que regulan los nuevos títulos universitarios y otra bien diferente lo que se hace en el espacio y tiempo real y vital de un aula universitaria, y que, tal vez, los buenos y malos profesores del antiguo modelo universitario seguirán siendo los mismos -buenos o malos, respectivamente- en el nuevo. Y, sin embargo, constatar esto -saber que en, el fondo, quien desee lograr ser el buen profesor al que aspira encontrará en el 
nuevo modelo oportunidades para lograrlo- no es suficiente para permanecer en silencio al respecto de algunas cosas. Como cuando se afirma, como lo hacía en el año 2008 Cristina Garmendia, que "las humanidades tienen que implicarse mucho más de lo que están en el campo científico y tecnológico. Y esto implica un cambio de actitud: en este ministerio encontrarán la puerta abierta para analizar aquellos proyectos que nos presenten" (Garmendia, 2008).

Estas palabras, en mi opinión, esconden la pretensión de hacer pasar por investigación humanística lo que en realidad no es sino un trabajo técnico-instrumental que favorece los aspectos instrumentales de dichas investigaciones cuando son susceptibles de producir determinados rendimientos tecno-económicos, con la consecuencia de una devaluación de su elemento más sustantivo. De este modo, la investigación dejará de realizarse y de prosperar por su propio interés. El principio de rentabilidad y demanda social predomina aquí sobre cualquier otro y favorece, como de hecho se ha producido ya, la introducción "en el orden del saber del aparato bancario de medida", tornándose equivalentes dominios que antes no lo podían ser de ningún modo, porque todos quedan igualados al traducirse a un número de créditos. Esta unidad de medida y de valor conferida a las "asignaturas" hace de ellas "conocimiento en general", sin mayor distinción de contenidos realmente relevantes. Así, como decía Claudio Magris en un artículo publicado en el Corriere Della Sera el 22 de diciembre de 1999:

Hasta ahora se valoraba a un estudiante sobre la base de lo que demostraba saber, durante la prueba de un examen, acerca de la disciplina en cuestión y sobre la base de la inteligencia y la capacidad crítica con las que demostraba saber interpretar y reelaborar las nociones de las que se tratara. Era asunto suyo haber empleado uno o tres meses para entender un teorema o un acto del Hamlet. Ahora parece perfilarse la tendencia a cuantificar (en créditos) cualquier actividad de un estudiante, escolar y extraescolar: parece que no debiera quedar nada que fuera gratuito (Magris, 2008, 175).

José Luis Pardo comenta que, de algún modo, todo ello parece la consecuencia de una tendencia que, en 1857, llevó a Marx a escribir lo siguiente:

La indiferencia respecto del trabajo determinado corresponde a una forma de sociedad en la cual los individuos pueden pasar con facilidad de un trabajo a otro y en la que el género determinado del trabajo es fortuito y, por consiguiente, les es indiferente. En este caso el trabajo se ha convertido no sólo categóricamente sino realmente, en un medio de producir riqueza en general, y ha dejado de confundirse con el individuo en un destino especial (Marx, 2004, 187).

Esta sustitución del "trabajo particular" por el "trabajo en general", de la que hablaba Adam Smith, no deja de tener resonancias más que evidentes en la sustitución de los saberes concretos en "conocimiento en general", una especie de "gelatina de conocimiento humano indiferenciado" que hace posible que un profesor de lo que hasta hace bien poco era un departamento universitario pueda dedicarse a impartir cualquier clase de "asignatura" de su departamento, porque lo único 
UNA PEDAGOGÍA DE LA PRESENCIA. CRÍTICA FILOSÓFICA DE LA IMPOSTURA PEDAGÓGICA

que cuenta es que cumpla con una dedicación docente equivalente a una serie de créditos. La docencia no se valora ya por la dedicación a un saber sobre el que hay que profundizar y extender, y que tiene su propio rigor y dificultad -porque aprender es difícil, pero no imposible-, sino que se mide en términos de una serie de créditos de docencia, importando bastante menos el contenido de la misma.

En definitiva: la enseñanza es un tipo de actividad cuya temporalidad corresponde, por así decir, al tiempo de los hombres libres, una temporalidad que no es cronométrica, sino una que tiene que ver con la noción de un tiempo elástico y flexible. Como señala Pardo: “Cómo podrían las enseñanzas de estos hombres ser comprimidas en los rígidos moldes de una "clase", de un "curso" o de un "programa", siempre con sus límites explícitos y cronométricos y con su estructura clientelar?" (Pardo, 2004, 115).

\section{CONCLUSIÓN}

En un ensayo ya antiguo -Les charlatans de la nouvelle pédagogie-, escrito por Lucien Morin, un joven filósofo de la educación de origen americano, aunque establecido por aquella época en Quebec, y argumentado en un tono ácido que defendía posiciones bastante conservadoras, y por mi parte inasumibles, el autor se quejaba de lo que llamaba la "opinionitis pedagógica", rótulo que englobaba a esos educadores "desenfrenados" que, confundiendo la opinión con el saber, acababan por incurrir en lo que el autor llamaba "pedagogía de la existencia", siendo Rousseau, inevitablemente, el padre del pretendido mal. En un momento de su ensayo, podemos leer:

El exceso de pedagogía de la existencia ha engendrado el absurdo monstruo de la opinionitis pedagógica. La opinionitis pedagógica es el rechazo del sentido común y de la ciencia, la negación de la evidencia y de la realidad, y la deificación predicativa del subjetivismo, del relativismo, del pragmatismo y del naturalismo positivista (Morin, 1973, 108).

El lector que haya tenido la paciencia de llegar hasta aquí podría, advertidamente o no, pensar que el planteamiento que he defendido y los argumentos que he desarrollado en este artículo pueden formar parte de la mentada "pedagogía de la existencia”. Quiero aprovechar esta sección dedicada a las conclusiones para tratar de dilucidar hasta qué punto mi propia posición, en efecto, tiene que ver exactamente con ese rótulo, aunque en un sentido muy diferente al que el propio Morin tanto teme. Por supuesto, no me voy a detener en desmontar, porque no es del caso hacerlo aquí, las contradicciones en las que el propio Morin incurre al poner juntas expresiones tales como "sentido común y ciencia" o "relativismo y pragmatismo". Bastará leer con cierto cuidado a Descartes o a Montaigne para darse cuenta de ello.

Voy a tratar de resumir, por tanto, algunas ideas que, aunque provisionales, pueden muy bien servir a tal propósito y como conclusión de este texto. 
1. En primer lugar, del desarrollo anterior se deriva una primera conclusión: que quizá la única forma que tenemos de hacernos con lo real es el lenguaje (narrando, contando, expresando, actos todos ellos que forman parte del impulso activo del hombre sobre el mundo). Pero se trata del lenguaje entendido, no como un mero medio de comunicación, sino como el fin de toda comunicación genuinamente humana. Fuera del lenguaje - de la capacidad de narrar, contar, expresar, nombrar- la realidad es, sencillamente, muda, dramáticamente silenciosa. El mundo solo adquiere su forma y sentido en la mirada del hombre y, por tanto, a través de los recursos del lenguaje; pero en la medida en que el lenguaje depende de la cultura, la palabra inventa en el interior de lo real una dimensión propia donde se entrelazan lo social y una relación más amplia con el mundo (Breton y Le Breton, 2011, 106). Es posible que no existan palabras capaces de decir lo real en determinadas circunstancias, bajo el impacto de acontecimientos que son refractarios al lenguaje; pero, incluso a pesar de ello, la experiencia de la realidad tiene voz, aunque no siempre acceda a la palabra o al lógos. Del mismo modo, uno puede aceptar que hay algo más, algo que trasciende lo real y los marcos de todo tipo desde los cuales el hombre capta o accede a lo que hay. Pero las cosas no simplemente son; además, nos pasan; y por eso solo podemos acceder a ese límite que nos trasciende (y que trasciende la realidad inmediata) desde un encuentro ético, estético y existencial con lo real, es decir, desde un espacio y desde un tiempo, desde un aquí y desde un ahora a través de la dimensión de la presencia. Eso, me parece, es inescapable. El encuentro con lo real es a menudo brutal. Y por eso construimos nuestras fábulas, nuestras ficciones, nuestras, por así llamarlas, pequeñas "mentiras". Esas fábulas, narraciones y mentiras son lenguaje. Y el lenguaje hace, o deshace, mundos. Además, hay una pluralidad de lenguajes para tratar de decir, nombrar, hacer presente, o hacernos presentes, en lo real. Sin experiencia del lenguaje no hay realidad, porque las cosas no existen fuera de esa experiencia. Y, desde luego, de eso se trata; de que no es lo mismo nombrar una determinada realidad educativa con unas palabras que con otras. La elección de la palabra no es inocente ni sus efectos inocuos (Bordelois, 2005).

2. En segundo lugar, se ha sugerido que al examen de la realidad le conviene o un tipo de distancia poética, es decir, una distancia apropiada -ni muy lejos ni muy cerca-, o dicho en otros términos, desde la experiencia de la presencia del sujeto en aquello que piensa o que hace. Por eso, de acuerdo con ésta, la potencia ya no es solo un poder hacer, sino un poder no hacer, la potencia de una impotencia. Para asegurar la libertad y la capacidad de resistencia frente al absolutismo dogmático de lo real, el hombre puede, y de hecho debe, abstenerse de hacer, pues no es cierto que "todo es posible". Es aquí donde se funda la crítica al principio, supuestamente democrático, de flexibilidad pedagógica.

3. En tercer término, la educación, entendida como un encuentro (y una transmisión) entre generaciones en la filiación del tiempo, está en el orden del acontecimiento. Esta dimensión del acontecimiento tiene importancia para la educación, sobre todo en un aspecto muy concreto: en el régimen de las transmisiones; en el enseñar y en el aprender. Creo que "transmitir" no se reduce al acto de 
volver accesible al aprendiz un cuerpo de información de manera indiferenciada y eficaz, gracias sobre todo a las nuevas tecnologías de la información. Es cierto que la transmisión de los saberes por vía electrónica está cada vez más extendida y es muy sofisticada; y me pregunto si, bajo tales condiciones, ciertas situaciones tradicionales de la enseñanza y del aprendizaje, que se fundaban en el cara a cara -en el régimen de la presencia- constituyen más bien un residuo de cierto "romanticismo caduco". Lo que yo pienso es que lo más interesante de toda relación de aprendizaje es, precisamente, ese "hacernos presentes en lo que hacemos", esa relación cara-a-cara, en lo que enseñamos y en lo que aprendemos. La aludida pedagogía de la presencia tiene aquí claramente su máxima relevancia: ¿Cómo nos hacemos presentes, cuando enseñamos y cuando aprendemos, en eso que nos pasa al transmitir y al recibir, al enseñar y al tratar de comprender, y siempre en relación al objeto que media en la relación profesor-alumno? Las tesis desarrolladas por Rancière en El maestro ignorante tienen, en este punto, una potencia de sentido para una reconstrucción de la experiencia del aprender. Pues es cierto que lo que constituye el centro de toda reflexión filosófica sobre la educación tiene que ver con esto: alguien aprende algo y no se sabe ni cómo ni se puede anticipar. O dicho en los términos que ya fueron señalados más atrás: no hay una esencia de lo pedagógico, sino que es la propia experiencia -el acontecimiento- de una relación educativa lo que permite pensar qué significa ser un sujeto de la educación, qué significa lo pedagógico.

4. Finalmente, está el asunto de la gestualidad educativa. Una pedagogía de la presencia supone una temporalidad (educativa) muy diferente del tiempo cronométrico al que, las distintas y recientes reformas educativas, nos quieren acostumbrar. El tiempo de un hombre libre es, dicho muy sencillamente, el tiempo del hombre que dispone de un rato. Es un tiempo apropiado, una temporalidad en la que los gestos (en nuestro caso, los gestos educativos), más que estar prescritos pedagógicamente aparecen a medida que uno se hace presente en aquello en lo que está cuando enseña, cuando transmite, cuando se para a pensar en lo que hace, cuando se demora, cuando escucha y espera. El gesto educativo, que es el lugar donde educador y educando esperan, soportan y asumen lo que les pasa en su encuentro, es lo imprescriptible, una revelación más que un dictado. Junto a lo que conocemos y ya sabemos es preciso hablar de lo que ignoramos. Hay modos de no saber que producen torpeza por desatención y modos de no saber que son belleza y búsqueda. Los gestos educativos de los que hablo se inscriben aquí. Está bien que la epistemología y la ciencia del método, también en pedagogía, fijen algunas condiciones, paradigmas, modelos, estatutos del saber. Pero quizá nos falta algo central: aprender a articular una zona de no conocimiento, nuestras zonas de ignorancia. Aprender a mantenerse en la justa relación con una ignorancia, dejarnos guiar por un no conocimiento que acompaña nuestros gestos.

Si la educación tiene algún sentido es porque en los distintos escenarios educativos que transitamos a lo largo de nuestra vida algo nos pasa. Pero no siempre nos damos cuenta de ello. No se trata de hacer de la educación la enseñanza del arte de vivir, pues no creo posible que dicho arte se pueda enseñar por una vía 
directa. Más bien tiendo a considerar que la educación tiene que ver, en ese encuentro entre generaciones, con la transmisión del mundo y sus distintas imágenes. Por eso no creo posible pensar una pedagogía que no sea, al mismo tiempo, una pedagogía del mundo en la que cada ser humano, cada existente, tenga la posibilidad de aprender a encontrar su propio arte de vivir. Es en este sentido en el que, de defender alguna clase de pedagogía, la mía sería una pedagogía del existente. Ahora bien: ese arte de vivir, ese dar forma a nuestra vida que, porque somos mortales, frágiles y dependientes, a cada momento se nos escapa, no es, me parece, otra cosa que la capacidad -potencia e impotencia al mismo tiempo, posibilidad y límite- de mantenernos en relación armónica (ética y estética) con lo que se nos escapa.

\section{REFERENCIAS BIBLIOGRÁFICAS}

Adorno, Th. (2003) El ensayo como forma, en Notas sobre literatura, Obra Completa, 11. Madrid, Akal, 11-34.

Agamben, G. (2001) Medios sin fin. Valencia, Pre-Textos.

- (2011) Sobre lo que podemos no hacer, en Desnudez. Barcelona, Anagrama.

ARENDT, H. (1993) La condición humana. Barcelona, Paidós.

ARISTÓTELES (2011) Metafísica. Madrid, Gredos.

BÁrcena, F. (2011) Philosophy of Education, the Production of the Presence and the Poetic Distance. Bajo Palabra, n. ${ }^{\circ}$ 6, 27-28.

- (2012) El eterno aprendiz. Filosofía, educación y el arte de vivir. Buenos Aires, Miño y Dávila.

BellaH, R. (1989) Hábitos del corazón. Madrid, Alianza.

Biesta, G. (2011) Aprendiz, estudiante, hablante. ¿Por qué importa cómo llamamos aquellos a quienes enseñamos?, en Simons, M.; MAsschelein, J. y LARrosa, J. (eds.) Jacques Rancière. La educación pública y la domesticación de la democracia. Buenos Aires, Miño \& Dávila, 149-176.

Bordelois, I. (2005) La palabra amenazada. Buenos Aires, Libros del Zorzal.

Breton, Ph. y Le Breton, D. (2011) El silencio y la palabra contra los excesos de la comunicación. Buenos Aires, Nueva Visión.

CERletTI, A. (2008) La política del maestro ignorante: la lección de Rancière. Educ. Soc., Campinas, vol. 24, n. $^{\circ} 82$.

Comte-SPonville, A. (1989) Une éducation philosophique. París, Puf.

CuA, A. (1998) Moral vision and tradition. American University Press.

Deleuze, G. (1968) Différence et repetition. París, Puf.

- (1996) Proust y los signos. Barcelona, Anagrama.

- (2005) Lógica del sentido. Barcelona, Paidós.

Descartes, R. (1983) Meditaciones metafísicas. Madrid, Austral.

D'Hoest, F. (2011a) Cierta experiencia de la distancia en educación. Sobre "El hijo" de los Dardenne. Bajo Palabra, n. ${ }^{\circ}$ 6, 73-82.

- (2011b) Cómo hacer palabras sin cosas. Resonancias de Rancière en Canino, y viceversa, en Simons, M.; MASSCHElein, J. y LARROSA, J. (eds.) Jacques Rancière. La educación pública y la domesticación de la democracia. Buenos Aires, Miño \& Dávila, 233-252.

Didi-Huberman, G. (2008) Cuando las imágenes toman posición. Madrid, Antonio Machado Libros. 
UNA PEDAGOGÍA DE LA PRESENCIA. CRÍTICA FILOSÓFICA DE LA IMPOSTURA PEDAGÓGICA

Foucault, M. (1966) Les mots et les choses. París, Gallimard.

- (2000) Nietzsche, la genealogí, la historia. Valencia, Pre-Textos.

- (2002) Hermenéutica del sujeto. Curso en el Collège de France, 1981-1982. México, FCE.

- (2003) La voluntad de saber. México, Siglo XXI editores.

GABRIEL, G. (2007) ¿La lógica como literatura? Observaciones sobre el significado de la forma literaria en Wittgenstein, en HADOT, P. Wittgenstein y los limites del lenguaje. Valencia, Pre-Textos.

Garmendia, C. (2008) Los apuntes van a desaparecer. Entrevista con Cristina Garmendía. El País, 7 de junio.

Giddens, A. (2006) Mejorar las universidades europeas. El País, 10 de abril de 2006.

Gil CANTERO, F. (2011) "Educación con teoría”. Revisión pedagógica de las relaciones entre la teoría y la práctica educativa. Teoría de la Educación. Revista Interuniversitaria, 23: $1,19-43$

Ginzburg, L. (1952) Carta a Regine Coeli, en Malvezzi, P. y Pirelli, G. (eds.) Lettere di condannati a morte della Resistenza italiana. Turín, Einaudi, 148-149.

GonzÁlvez Pérez, V. (2010) Hacia una reconstrucción de la razón pedagógica. Teoría de la Educación, Revista Interuniversitaria, 22: 2, 19-42.

Gumbrecht, H. von (2010) Éloge de la présence. Ce qui échappe à la signification. París, Maren Stell.

Hadot, P. (2000) ¿Qué es la filosofía antigua? México, Fondo de Cultura Económica.

- (2001) La philosophie comme manière de vivre. París, Albin Michel.

- (2004a) Apprendre à philosopher dans l'Antiquité. París, Librarie Générale Française.

- (2004b) Le Voile d'Isis. París, Gallimard.

- (2006) Ejercicios espirituales y filosofía Antigua. Madrid, Siruela.

- (2007) Wittgenstein y los límites del lenguaje. Valencia, Pre-Textos.

- (2010) No te olvides de vivir. Goethe y la tradición de los ejercicios espirituales. Madrid, Siruela.

Holma, K. (2009) The Strict Analysis and the Open Discussion. Journal of Philosophy of Education, 43, 3, 325-338.

IBÁÑEz, T. (2005) Contra la dominación. Variaciones sobre la salvaje exigencia de libertad que brota del relativismo y de las consonancias entre Castoriadis, Foucault, Rort y Serres. Barcelona, Gedisa.

Jасотот, J. (2008) Enseñanza universal. Lengua maternal. Buenos Aires, Editorial Cactus.

JódAr, F. (2007) Alteraciones pedagógicas. Barcelona, Laertes.

Larrosa, J. (1995) Tecnologías del yo y educación. Notas sobre la construcción y la mediación pedagógica de la experiencia de sí, en Larrosa, J. (ed.) Escuela, poder y subjetivación. Madrid, La Piqueta.

- (2010) Herido de realidad y en busca de realidad. Notas sobre los lenguajes de la experiencia, en Contreras, J. y PéRez, N. (eds.) Investigar la experiencia educativa. Madrid, Morata, 86-116.

LEPENIES, W. (2008) ¿Qué es un intelectual europeo? Barcelona, Galaxia Gutenberg-Círculo de Lectores.

Machado, A. (2003) Juan de Mairena. Madrid, Cátedra.

MAgris, C. (2008) Empresarialismo universal, en La historia no ha terminado. Ética, política, laicidad. Barcelona, Anagrama.

Manen, Max van (2003) Investigación educativa y experiencia vivida. Barcelona, Idea Books.

MARTín, A. y BARRIENTOS, O. (2009) Los dominios del pensamiento crítico: una lectura desde la teoría de la educación. Teoría de la Educación. Revista Interuniversitaria, 21: 2, 19-44. 
UNA PEDAGOGÍA DE LA PRESENCIA. CRÍTICA FILOSÓFICA DE LA IMPOSTURA PEDAGÓGICA

MARX, K. (2004) Introducción a la contribución de la crítica de la economía política, en Contribución a la crítica de la economía política. Granada, Comares.

Masschelein, J. (2001) The Discourse of Learning Society and the Loss of Chilhood. Journal of Philosophy of Education, 30: 1, 1-20.

- (2009) On Fieldwork in Philosophy and the Actual Need for Laboratories. A proposal and invitation. Conferencia leída en la International Conference: "Philosophy of Education and the Transformation of Educational Systems", Universidad de Basel, octubre 2009. Documento enviado por el autor.

MÈLICH, J.-C. (2010) Ética de la compasión. Barcelona, Herder.

MondZain, M. J. (2007) Homo spectator. París, Bayard.

MOORE, T. W. (1974) Educational Theory. An Introduction. Londres, RKP.

- (1982) Philosophy of Education. An Introduction. Londres, RKP.

Morey, M. (2007) Pequeñas doctrinas de la soledad. México, Sexto Piso.

Morin, L. (1973) Los charlatanes de la nueva pedagogía. Barcelona, Herder.

Nehamas, A. (2005) El arte de vivir. Reflexiones socráticas de Platón a Foucault. Valencia, Pre-Textos.

NorTh, P. (2012) The Problem of Distraction. Nueva York, Stanford University Press.

Nussbaum, M. C. (2003) La terapia del deseo. Teoría y práctica en la ética helenística. Barcelona, Paidós.

Olbadia, C. (1995) L'esprit de l'essay. De Montaigne à Borges. París, Éditions du Seuil.

PARDo, J. L. (2004) La regla del juego. Sobre las dificultades de aprender filosofía. Barcelona, Círculo de Lectores-Galaxia Gutenberg.

- (2010) Nunca fue tan hermosa la basura. Artículos y ensayos. Barcelona, Galaxia Gutenberg-Círculo de Lectores.

Pennac, D. (2007) Chagrin d'École. París, Gallimard.

Prieto Egido, M. (2011) La relación educativa como ejercicio de distancia. Una mirada a la experiencia compasiva desde Rousseau. Bajo Palabra, n. ${ }^{\circ}$ 6, 135-144.

Puelles Romero, L. (2011) Mirar al que mira. Teoría estética y sujeto espectador. Madrid, Abada editores.

RANCIÈRE, J. (1987) Le maître ignorant. París, Fayard.

- (2008) L'espectateur émancipé. París, La Fabrique éditions.

RutTenberg, C. (ed.) (2009) What do Philosophers of Education do? (And how do they do it?). Journal of Philosophy of Education, 43, 3. (Special Issue).

SÁNCHEZ FERLOSIO, R. (2002) La hija de la guerra y la madre de la patria. Barcelona, Destino.

SERres, M. (1993) O terceiro instruido. Lisboa, Instituto Piaget.

STAL, I. (2008) L'imposture pédagogique. París, Perrin.

Steiner, G. (1989) Presencias reales. Barcelona, Destino.

Stiegler, B. (2008) Prendre soin de la jeunesse et des génerations. París, Flammarion.

- (2010) Ce qui fait que la vie vaut la peine d'être vécue. De la pharmacologie. París, Flammarion.

Storme, Th. y Vlieghe, J. (2011) The Experience of Chilhood and the Learning Society: Allowing the Child to the Philosophical and Philosophy to be Childshid. Journal of Philosophy of Education, 45: 2, 183-198.

VOKey, D. (2009) "Anything You Can Do I Can Do Better": Dialectical Argument in Philosophy of Education. Journal of Philosophy of Education, 43, 3, 339-356.

WitTGEnSTEIN, L. (1989) Observaciones. México, Siglo XXI editores. 